\title{
REVIEWS
}

\section{Olfactory and other sensory impairments in Alzheimer disease}

Claire Murphy ${ }^{1,2}$

Abstract | The vast increase in Alzheimer disease (AD) worldwide has grave implications for individuals, family support systems and the health-care systems that will attempt to cope with the disease. Early markers of the disease are essential for efficient selection of clinical trial participants for drug development and for timely treatment once an intervention becomes available. There is avid interest in noninvasive, inexpensive markers that have the potential to identify prodromal AD. This Review considers sensory impairments that have the potential to serve as early indicators of $A D$, with a focus on olfaction, hearing and vision. Current evidence regarding the potential markers of $A D$ in each modality is examined, with a particular emphasis on olfaction and current findings that olfactory function is associated with prodromal AD. Research suggests that olfactory impairment is associated with other markers that signal the emergence of prodromal AD. Auditory impairment is associated with dementia in epidemiological studies and visual system deficits have been reported in AD; however, the emergence of these deficits in prodromal AD is unclear. Further research is necessary to address the relative sensitivity and specificity of olfactory, auditory and visual measures for the detection of prodromal AD.

Alzheimer disease (AD) is a devastating neurodegenerative disorder that affects 46.8 million people globally ${ }^{1}$ and is rising at an alarming rate as the population ages. The AD epidemic presents a major public health issue and has profound economic consequences for the individual and for society. In the USA alone, AD costs $>$ US $\$ 200$ billion per year in medical expenses, caregiving and lost income ${ }^{2}$. AD erodes memory and cognition and leaves patients unable to care for themselves. Despite intense efforts to develop effective pharmacological interventions, $\mathrm{AD}$ is currently incurable. As drugs for $\mathrm{AD}$ become available, determining the individuals who are at risk of $\mathrm{AD}$, predicting disease onset and progression, and characterizing the effectiveness of interventions will be crucial if treatment is to be applied before substantial neurological compromise. Sensory impairments have the potential to serve as very early disease indicators.

The central focus of this Review is the emerging evidence that olfactory impairments might reflect the onset of $\mathrm{AD}$, amnestic mild cognitive impairment (MCI) and the presence of amyloid- $\beta(\mathrm{A} \beta)$ and tau pathology in cognitively normal adults. Evidence is discussed from laboratory studies, Alzheimer Disease Research Center (ADRC) populations, epidemiological studies and community samples that supports the scientific premise that olfactory dysfunction occurs before cognitive impairment and the development of dementia in patients with $\mathrm{AD}$ and in those with a genetic risk of $\mathrm{AD}$ or with amnestic MCI and, thus, could be an inexpensive, noninvasive biomarker.

Although a complete understanding of the roles of $A \beta$ and tau, the hallmarks of $\mathrm{AD}$, is still developing, accumulation of tau in the presence of $\mathrm{A} \beta$ presages development of cognitive symptoms in $\mathrm{AD}^{3}$. No single biomarker or risk factor has been identified that completely predicts disease onset or progression of $\mathrm{AD}$; however, the levels of $A \beta$ and tau in cerebrospinal fluid (CSF) and reduced volume of the hippocampus on structural MRI are used as biomarkers in research and drug trials ${ }^{4}$. This Review considers emerging findings that suggest that olfactory impairment shows an association with CSF biomarkers of $\mathrm{AD}$ - such as the ratio of total levels of tau (t-tau) or levels of tau phosphorylated at threonine $181\left(\mathrm{P}_{181}\right.$-tau) to levels of $A \beta_{1-42}$ - in individuals with a heightened risk of $\mathrm{AD}^{5}$ and that olfactory impairment is associated with hippocampal atrophy in $\mathrm{AD}^{6,7}$ and entorhinal cortical thinning in preclinical disease ${ }^{7}$. Several studies from the past few years have established that hearing loss is associated with the development of cognitive impairment and dementia ${ }^{8-10}$. Furthermore, retinal thinning, decreased contrast sensitivity and reduced pupillary response have been demonstrated in the visual system in people with $\mathrm{AD}$. 


\section{Key points \\ - Brain areas involved in olfactory processing - such as the olfactory bulb and entorhinal cortex — show very early neuropathology in Alzheimer disease (AD), suggesting that olfactory function is a potential biomarker. \\ - Odour memory and odour identification are profoundly affected in individuals with $A D$ and in those at risk of $A D$, suggesting that several measures of olfactory function signal preclinical AD. \\ - Olfaction currently shows the greatest promise of all sensory biomarkers of AD; odour identification impairment predicts conversion to mild cognitive impairment $(\mathrm{MCl})$ in cognitively normal individuals and conversion to $A D$ in patients with amnestic $\mathrm{MCl}$, and shows substantial relationships with other biomarkers of $A D$. \\ - Epidemiological research indicates that hearing loss at baseline is associated with cognitive impairment and incident dementia over a 10 -year period. \\ - Visual changes in prodromal and clinical $A D$ include retinal thinning in $A D$, impaired contrast sensitivity in $\mathrm{AD}$ and mild $\mathrm{MCl}$, and abnormal pupillary responses that reflect cognitive load in $\mathrm{AD}$ and amnestic $\mathrm{MCl}$. \\ - Numerous sensory measures in olfaction, hearing and vision are emerging as potential markers of $A D$; further research is necessary to determine their relationship to other biomarkers and to assess their sensitivity and specificity for early prediction of AD.}

Thus, multiple potential markers exist in sensory domains, and this Review discusses emerging evidence and important unanswered questions. The need for further research to determine the relative sensitivity and specificity of potential novel, noninvasive biomarkers for $\mathrm{AD}$ is also considered.

\section{Populations at risk of AD}

Populations at an increased risk of $\mathrm{AD}$ include those with genetic risk, those with MCI and those with $\mathrm{A} \beta$ deposition in the brain. Altered sensory function in individuals without dementia in these populations has the potential to contribute to early diagnosis of disease.

The apolipoprotein $\mathrm{E}(A P O E)^{\star} \varepsilon 4$ allele is the most powerful genetic predictor of sporadic $\mathrm{AD}^{11}$. At least one $A P O E^{*} \varepsilon 4$ allele is present in $80 \%$ of patients with $\mathrm{AD}$. $A P O E^{\star} \varepsilon 4$ carriers are at an increased risk of $\mathrm{AD}$, develop

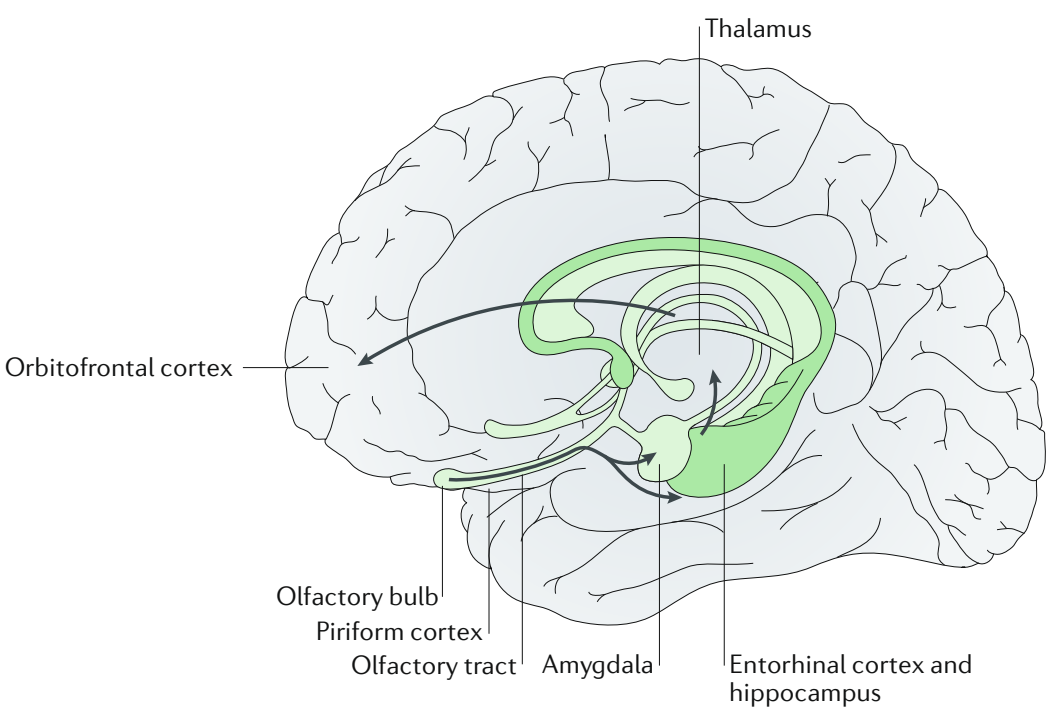

Fig. 1 | Regions crucial to olfactory processing. Regions that are involved in early olfactory processing include the olfactory bulb and tract, the piriform cortex, amygdala, entorhinal cortex and hippocampus. the disease earlier than non-carriers ${ }^{11}$ and have lower levels of the $\mathrm{AD}$ biomarker $\mathrm{A} \beta_{1-42}$. As many as $47 \%$ of individuals who carry one allele of $A P O E^{\star} \varepsilon 4$ and $90 \%$ of those who carry two alleles will develop $\mathrm{AD}^{11}$. This increased risk of $\mathrm{AD}$ makes $A P O E^{\star} \varepsilon 4$ carriers an especially relevant population in which to study the development of the disease in the silent preclinical stage. Clinical trials can be enriched with participants who are carriers of the $A P O E^{\star} \varepsilon 4$ allele because they have an increased likelihood of undergoing transitions in cognitive function over the course of a trial.

Individuals with MCI exhibit mild impairment in memory and cognition, but have intact global cognition and are able to perform activities of daily living ${ }^{12}$. These individuals are expected to develop $\mathrm{AD}$ at a rate of $\sim 15 \%$ per year. Among individuals with MCI, those with primary memory impairment are classified as amnestic $\mathrm{MCI}$ and have an increased likelihood of converting to $\mathrm{AD}^{13}$.

Cognitively normal individuals who are amyloid positive have an increased risk of developing $\mathrm{AD}^{14}$. CSF levels of $A \beta_{1-42}$ fall as amyloid accumulates in the brain and thus serve as a useful biomarker. Similarly, amyloid burden assessed by PET is a potential biomarker. However, the presence of amyloid is a risk factor rather than an indicator of disease, as a substantial proportion of patients with amyloid positive PET scans are cognitively normal. Patients who are amyloid positive and $A P O E^{\star} \varepsilon 4$ carriers are at an increased risk of transition to $\mathrm{MCI}$ and $\mathrm{AD}$.

\section{Olfaction}

Post-mortem studies indicate that pathological changes in $\mathrm{AD}$, particularly neurofibrillary tangles, occur very early in the disease in entorhinal and transentorhinal areas, the anterior olfactory nucleus and the olfactory bulb - regions involved in olfactory information processing. Importantly, AD neuropathology emerges in these areas before the onset of clinical symptomatology $^{15-23}$. Braak staging ${ }^{16-18,24-26}$ describes very early $\mathrm{AD}$ pathology in entorhinal and transentorhinal areas. As disease progresses, tangles develop in a characteristic pattern that shows heaviest involvement of the entorhinal cortex, perirhinal cortex, CA1 and subicular area of the hippocampus, and amygdala, before tangle pathology is observed in the cortices, which suggests that areas that are key to olfactory information processing have heavy tau pathology $y^{15,27}$. The Braak and Tredici hypothesis suggests very early involvement of the locus coeruleus $^{26}$, a structure that projects to the olfactory bulb, in $\mathrm{AD}$. The pattern of early and consistent involvement of these areas in AD neuropathology suggests that olfactory function might be particularly vulnerable in $\mathrm{AD}$ and might reflect the disease process (FIGS 1-3).

\section{Odour identification}

Odour identification involves detection and recognition of a previously smelled odour and recall of objects, sources, and/or names associated with the odour. A number of widely used tests of odour identification have been employed in the investigation of individuals with $\mathrm{AD}$ and those at risk of $\mathrm{AD}(\mathrm{BOX} 1)$. 


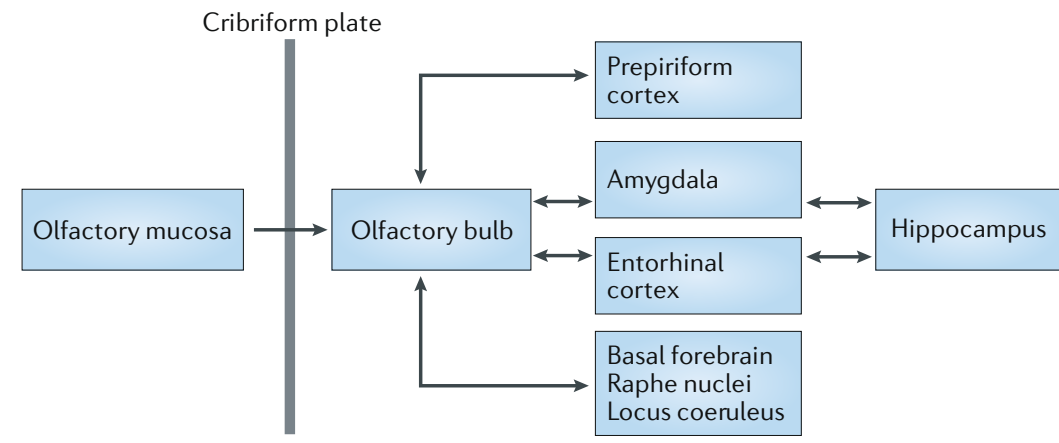

Fig. 2 | Olfactory processing areas affected in Alzheimer disease. Areas crucial to olfactory processing are well-established to show early neurodegenerative changes in Alzheimer disease, including the locus coeruleus, olfactory bulb, prepiriform cortex, entorhinal cortex and hippocampus. Adapted with permission from REF. ${ }^{15}$, Wiley-VCH.

Alzheimer disease. Following initial observations by Waldton $^{28}$, identification of odours is well-established to be profoundly impaired in patients with AD. The results are robust across a large number of studies that have used a variety of odorants and odour identification test formats ${ }^{28-36}$. Studies indicate that $\sim 85-90 \%$ of patients with $\mathrm{AD}$ have impaired odour identification ${ }^{34}$. The sensitivity and specificity for discrimination of patients with $\mathrm{AD}$ from healthy controls varies somewhat across measures but the correct classification rate has been reported to be $\sim 85 \%^{32,34}$. Impairment is increased in patients with $\mathrm{AD}$ who have the $A P O E^{\star} \varepsilon 4$ allele and dramatically so in those with two $A P O E^{\star} \varepsilon 4$ alleles ${ }^{33}$. Two meta-analyses comparing relative effect sizes of a number of existing olfactory tests found robust mean effect sizes for odour identification both for $\mathrm{AD}(d=2.05)^{36}$ and for MCI $(d=-0.86)^{37}$, suggesting that olfactory deficits have promise as potential biomarkers; however, these analyses are limited by the low number of studies that have used measures other than odour identification. Sensory, cognitive and semantic abilities are required for accurate odour identification; thus, compromised function of individual abilities or of a combination of abilities might underlie the profound impairment of odour identification in $\mathrm{AD}$.

Populations at risk of $A D$. Odour identification is impaired in cognitively normal elderly adults with the $A P O E^{\star} \varepsilon 4$ allele $^{38-40}$. This impairment has been confirmed in large population-based studies ${ }^{39,40}$. Notably, individuals with anosmia (that is, a complete loss of olfactory function) with the $A P O E^{\star} \varepsilon 4$ allele show an increased rate of development of $\mathrm{AD}$ over a 2 year period compared with individuals with normal olfaction ${ }^{39}$. Importantly, odour identification impairment exists in $A P O E^{\star} \varepsilon 4$ carriers before impairment on standard measures of dementia such as the Dementia Rating Scale $\left(\mathrm{DRS}^{41}\right)^{42}$. In one study of cognitively normal $A P O E^{\star} \varepsilon 4$ carriers, odour identification declined substantially over a 4-year period whereas DRS scores remained stable ${ }^{42}$, suggesting that odour identification could be more sensitive than DRS scores in detecting very early decline.

Homozygous $A P O E^{\star} \varepsilon 4 / \varepsilon 4$ individuals diagnosed with $\mathrm{AD}$ have a higher amyloid burden and a more rapid rate of cognitive decline than heterozygous $A P O E^{\star} \varepsilon 3 / \varepsilon 4$ carriers. Accordingly, homozygous $A P O E^{\star} \varepsilon 4 / \varepsilon 4$ carriers also show greater impairments than heterozygous $A P O E^{\star} \varepsilon 3 / \varepsilon 4$ carriers in odour identification that could surpass impairments in other domains, such as vision. When comparing the San Diego Odor Identification Test with the Boston Naming Test (a visual confrontational naming task that requires identification of line drawings and is used in many neuropsychology batteries for assessing $\mathrm{AD}$ ) in patients with $\mathrm{AD}$, homozygous $A P O E^{\star} \varepsilon 4 / \varepsilon 4$ individuals showed significantly more impairment of odour identification than heterozygous $A P O E^{\star} \varepsilon 3 / \varepsilon 4$ individuals and homozygous $A P O E^{\star} \varepsilon 3 / \varepsilon 3$ individuals, but no statistically significant group differences were detected in the Boston Naming Test ${ }^{33}$. In the Betula Study, a large population study in Sweden, decline in odour identification was observed in middleaged individuals and the rate of this decline was twice as rapid in homozygous $A P O E^{\star} \varepsilon 4 / \varepsilon 4$ individuals as in those who did not carry an $A P O E^{\star} \varepsilon 4$ allele $^{43}$.

Impairment of odour identification has also been well established in $\mathrm{MCI}^{14,42-48}$. Among cognitively normal individuals, those with poor odour identification scores at baseline are more likely to develop MCI than those with good odour identification scores ${ }^{45,46,48}$, and individuals with MCI who have odour identification impairment are more likely to show progressive cognitive decline $e^{35,37}$ and convert to $\mathrm{AD}^{35}$ than those without such impairment. Several studies have found that patients with the amnestic subtype of MCI show increased impairment of odour identification compared with non-amnestic $\mathrm{MCI}^{14,47,48}$, although one study did not detect such a difference ${ }^{49}$. Patients with multiple domain amnestic MCI have also been reported to show poorer olfactory function than patients with other subtypes ${ }^{47,48}$, which suggests that those at highest risk of conversion from MCI to AD show the greatest impairment on olfactory testing ${ }^{14,47,48}$. One study compared the use of several versions of an odour identification test for clinical trials and reported that the sensitivity and specificity of such a test to detect conversion from amnestic MCI to AD (receiver operating characteristic (ROC) area under the curve (AUC) 0.61-0.65) was similar to that of more expensive and invasive markers - that is, somewhat inferior to structural MRI (ROC AUC of 0.69-0.73) but similar to CSF biomarkers (ROC AUC of 0.63-0.67) ${ }^{35}$. Research from the University of California San Diego ADRC comparing a number of measures of olfactory function suggests that ROC AUC for odour familiarity, a form of remote odour memory, predicts conversion to $\mathrm{AD}$ from $\mathrm{MCI}$ in those who are $A P O E^{\star} \varepsilon 4$ carriers better than odour identification but that a combination of the two measures provides the best prediction (P. Wheeler and C.M., unpublished observations).

Elderly adults without dementia. Detection of preclini$\mathrm{cal} \mathrm{AD}$ in the general population is crucial for the identification of individuals who could benefit most from new disease-modifying drugs and treatments as these become available. Population studies of typically ageing adults have reported that olfactory dysfunction increases with age $\mathrm{e}^{50}$. Within these populations are individuals 
Transentorhinal Braak stage I-II
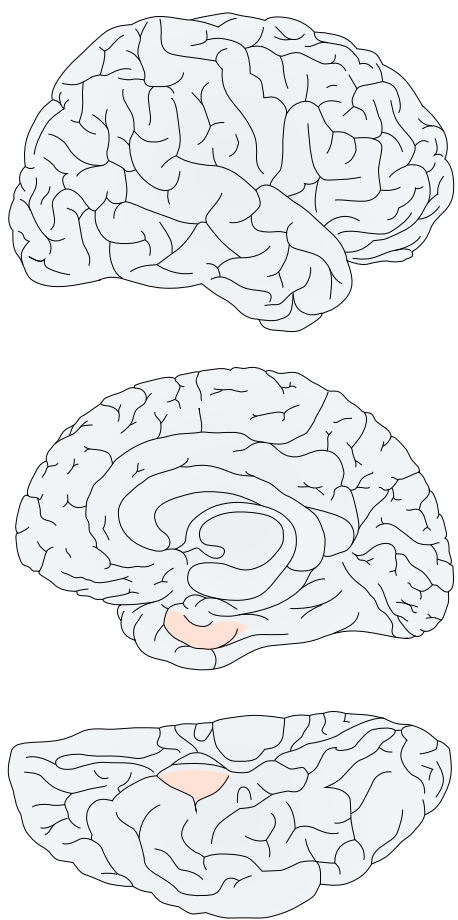

Limbic

Braak stage III-IV
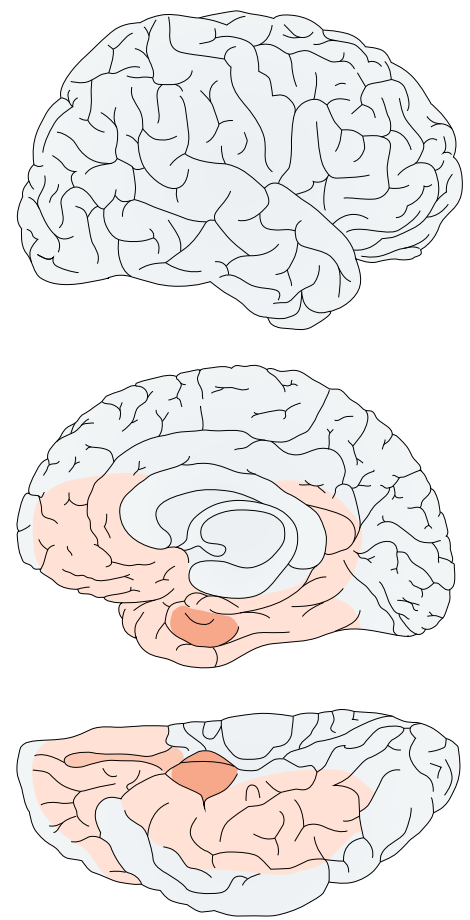

Isocortical

Braak stage V-VI
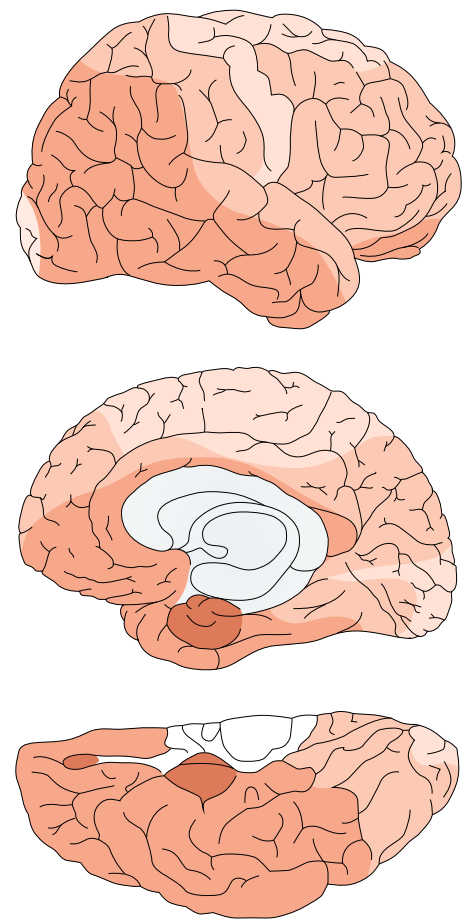

Fig. 3 | Braak staging of neurofibrillary changes in prodromal and clinical Alzheimer disease. Tau pathology (orange) occurs in the entorhinal cortex very early in Alzheimer disease. Lesions in the entorhinal cortex disrupt the flow of incoming olfactory information to the hippocampus and would be expected to affect performance on odour memory and odour identification tasks. Reproduced with permission from REF. ${ }^{24}$, Springer Nature Limited.

with undetected preclinical disease, whose decline in olfactory dysfunction probably contributes to the population estimates of olfactory impairment. Evidence of olfactory dysfunction in clinically normal elderly adults who go on to develop cognitive impairment, dementia or $\mathrm{AD}$ has emerged in a number of large-scale studies. Impairment of odour identification at baseline predicted cognitive impairment after 5 years in the Beaver Dam epidemiological study ${ }^{51}$. Predictions from olfactory impairment were more accurate than those from either hearing or vision impairment ${ }^{52}$. Impairment of odour identification predicted the development of MCI in individuals with intact cognitive function in the Rush Memory and Ageing Project, despite controlling for age, sex, education, $A P O E^{\star} \varepsilon 4$ status, and episodic memory function ${ }^{46}$. Similarly, in a cohort of elderly adults in a multi-ethnic community in Northern Manhattan ${ }^{53}$, impairment of odour identification predicted transition to dementia in cognitively normal individuals. Interestingly, odour identification predicted transition to $\mathrm{AD}$ better than a measure of immediate recall. In the Health, Ageing and Body Composition (Health ABC) study, individuals with performance in the poor or moderate tertiles of odour identification showed increased risk of dementia relative to those in the good tertile of odour identification ${ }^{48}$.

Thus, a large number of studies, a substantial number of which were published in the past 2 years, demonstrate that odour identification discriminates between cognitively normal individuals and those at risk of $\mathrm{AD}$, and between individuals with dementia or AD and those at risk of these conditions. Some of these studies have considered the relationship between odour identification and other biomarkers of dementia and some have tested the predictive power of odour identification for conversion to MCI or dementia. TABLE 1 summarizes the results of key studies that have characterized odour identification in populations at risk of dementia and/or have investigated the ability of odour identification as a marker to discriminate among groups and to predict conversion to MCI and dementia.

\section{Odour memory}

Odour memory requires the detection of an odour, the encoding of that event and subsequent retrieval of the event either by recalling the name of the odour or recognizing that it was previously presented. This odour memory sequence does not require the participant to name the odour, although individuals often report that they attempt to name the odour and use the name in their memory retrieval effort. Existing tests of odour memory require greater testing time than odour identification tests do, and this difference probably accounts for the relative paucity of studies of odour memory in people with $\mathrm{AD}$ and in individuals at risk of $\mathrm{AD}$. A number of tests of odour memory have been developed that assess multiple aspects of memory processing mediated by mesial temporal lobe (MTL) structures that are vulnerable in early AD. For example, the California Odor Learning Test ${ }^{54}$, an olfactory analogue of the California Verbal Learning Test ${ }^{55}$, produces measures of odour working memory, recall and recognition at short and 


\section{Box 1 | Odour identification tests widely used for assessment in dementia}

\section{NIH Toolbox Odor Identification Test ${ }^{95}$}

The NIH Toolbox Odor Identification Test assesses odour identification for common odours, microencapsulated and presented on business card-sized cards. The response mode includes four alternatives, presented as pictures and words. Normative testing was performed on a population of 2,884 individuals. The test is easily and inexpensively administered in 5 minutes or less.

\section{Odor Stick Identification Test for Japanese people ${ }^{96}$}

The Odor Stick Test for Japanese people uses microencapsulated odours, presented in a solid cream. The response cues include both pictures and words. The test is culturally valid, with odours appropriate for the assessment of olfactory function in Japanese people in a range of age groups.

\section{San Diego Odor Identification Test ${ }^{97}$}

The San Diego Odor Identification Test uses common natural odour items presented in opaque jars with a picture board to aid identification. It is designed to be given in 6 minutes, inexpensively, by non-experts. Test-retest reliability in elderly adults is very high. The format has facilitated its use in population studies and in individuals with cognitive impairment.

\section{Scandinavian Odor Identification Test ${ }^{98}$}

The Scandinavian Odor Identification Test uses odours chosen to be culturally valid for clinical use with Scandinavian people, and a four-alternative written response mode. Designed to be given by assistants with minimal training, it can be administered in 10-15 minutes. The test has been used in clinical research and in Scandinavian population studies.

\section{Sniffin' Sticks ${ }^{99}$}

The Sniffin' Sticks tests include an odour identification test in which odours are presented via a felt tipped pen-like device. The response mode is four alternatives. Designed by ear, nose and throat (ENT) researchers, it has been administered in ENT offices and has been used in research studies. It is commercially available.

\section{University of Pennsylvania Smell Identification Test ${ }^{100}$}

The University of Pennsylvania Smell Identification Test (UPSIT) contains 40 microencapulated scratch-and-sniff odours, each presented on one page in one of four booklets. The response mode is a four-alternative list of words describing odour objects. It was designed to be mailed to individuals for self-administration but has been used in alternative administrations. The UPSIT and a number of variations are commercially available. in odour recognition memory were associated with the $A P O E^{\star} \varepsilon 4$ allele, thinning of the entorhinal cortex and deterioration in Logical Memory scores in participants who were cognitively normal or who had memory concerns. Interestingly, healthy controls with POEM scores below those predicted by their identification and discrimination scores showed greater association with $A P O E^{\star} \varepsilon 4$ status, entorhinal thinning and trajectory on the memory task than did individuals in the lowest quartile of the odour identification scores, suggesting the potential of odour memory to signal risk of $\mathrm{AD}$.

Studies that have focused on memory in people with $\mathrm{AD}$ and/or in $A P O E^{\star} \varepsilon 4$ carriers have established the presence of a profound loss of odour memory in $A P O E^{\star} \varepsilon 4$ carriers on the basis of behavioural tests ${ }^{57-59,61}$. Deficits in odour recognition memory develop early during the progression of dementia in $A P O E^{\star} \varepsilon 4$ carriers. One report demonstrated differences in neuronal networks between elderly $A P O E^{\star} \varepsilon 4$ carriers and non-carriers during a cross-modal odour recognition memory task ${ }^{62}$. The results were profound: $A P O E^{\star} \varepsilon 4$ carriers and $A P O E^{\star} \varepsilon 4$ non-carriers showed differential connectivity both when odour items were correctly identified and during false alarms, with frontal-temporal disconnection indicated by models of the $A P O E^{\star} \varepsilon 4$ carriers. These findings suggest that during odour memory processing, $A P O E^{\star} \varepsilon 4$ carriers might recruit from other neural networks as a means of compensation for inefficient processing.

\section{Odour threshold}

Odour identification involves numerous aspects of cognitive processing, whereas odour threshold - that is, the lowest concentration at which a person can detect odour - is considered a more purely olfactory task. Odour threshold tests include trials with odour and no odour and thus participants probably make a comparison between the current trial and previous trials to help them to determine the presence of an odour, a process that involves aspects of working memory. Odour threshold testing requires many trials with appropriate inter-trial intervals to prevent adaptation, and thus would be difficult to incorporate into a study with limited testing time. Few studies have used this technique and fewer still have compared threshold impairment with other measures of olfactory dysfunction.

Nevertheless, odour threshold sensitivity has been demonstrated to be profoundly affected in $\mathrm{AD}^{30,45,63}$ and the degree of threshold impairment is associated with the degree of dementia ${ }^{63}$. $A P O E^{\star} \varepsilon 4$ carriers who are cognitively normal and subsequently go on to develop $\mathrm{AD}$ show odour threshold impairment in the year before converting to an $\mathrm{AD}$ diagnosis ${ }^{64}$. Poorer thresholds are seen in AD than in MCI and in MCI than in cognitively normal individuals ${ }^{43}$. The combination of odour identification and odour threshold testing increases the correct classification rate of healthy control individuals from individuals with $\mathrm{AD}$ or individuals with $\mathrm{MCI}$ over odour identification alone ${ }^{43}$. Altered odour thresholds in patients with $\mathrm{AD}$ or MCI suggest that the peripheral level of the olfactory system is substantially affected in the disease process. 
Table 1 | Odour identification in populations at risk of Alzheimer disease

\begin{tabular}{|c|c|c|c|}
\hline Reference & Population (number of participants) & $\begin{array}{l}\text { Odour identification } \\
\text { test }\end{array}$ & Results \\
\hline $\begin{array}{l}\text { Calhoun-Haney } \\
\text { \& Murphy } \\
(2005)^{42}\end{array}$ & $\begin{array}{l}\text { Cognitively normal; } \varepsilon 4 \text { carriers ( } 22), \varepsilon 4 \text { non- } \\
\text { carriers (28) }\end{array}$ & $\begin{array}{l}\text { San Diego Odor } \\
\text { Identification Test }\end{array}$ & $\begin{array}{l}\text { Carriers of the } \varepsilon 4 \text { allele showed significant decline } \\
(P<0.007) \text { over } 4 \text { years on odour identification but not on } \\
\text { dementia rating scale }\end{array}$ \\
\hline $\begin{array}{l}\text { Conti et al. } \\
(2013)^{128}\end{array}$ & $\begin{array}{l}\mathrm{MCl}(88), \text { normally ageing control } \\
\text { individuals (46) }\end{array}$ & $\begin{array}{l}\text { Culturally Adapted } \\
\text { Smell Identification Test }\end{array}$ & $\begin{array}{l}\text { Pathological odour identification was associated with } \\
\text { progression to dementia in } 2 \text { years }(P=0.03)\end{array}$ \\
\hline $\begin{array}{l}\text { Devanand et al. } \\
(2000)^{93}\end{array}$ & $\mathrm{MCl}(90)$ & UPSIT & $\begin{array}{l}\text { Patients with } \mathrm{MCl} \text { and poor odour identification with } \\
\text { unawareness of the loss had increased incidence of } \mathrm{AD} \\
\text { at follow-up }(P<0.0001)\end{array}$ \\
\hline $\begin{array}{l}\text { Devanand et al. } \\
(2010)^{44}\end{array}$ & $\begin{array}{l}\text { aMCl (170), non-amnestic } \mathrm{MCl}(120), \text { no } \\
\mathrm{MCl}(802)\end{array}$ & UPSIT & $\begin{array}{l}\text { Poorer odour identification in aMCI than in no } \mathrm{MCl} \text { in } \\
\text { multi-ethnic community sample }(P<0.001)\end{array}$ \\
\hline $\begin{array}{l}\text { Djordjevic, et al. } \\
(2008)^{45}\end{array}$ & $\begin{array}{l}\mathrm{AD}(27), \mathrm{MCl}(51) \text {, normally ageing control } \\
\text { individuals (33) }\end{array}$ & UPSIT & $\begin{array}{l}\text { Poorer odour identification in patients with } \mathrm{MCl}(P<0.001) \\
\text { and } \mathrm{AD}(P<0.001) \text { than in control individuals }\end{array}$ \\
\hline $\begin{array}{l}\text { Eibenstein et al. } \\
(2005)^{129}\end{array}$ & $\begin{array}{l}\mathrm{MCl}(29), \text { normally ageing control } \\
\text { individuals (29) }\end{array}$ & $\begin{array}{l}\text { Sniffin' Sticks Screening } \\
\text { Test }\end{array}$ & $\begin{array}{l}\text { Olfactory performance was poorer in patients with } \mathrm{MCl} \\
\text { than in normally ageing control individuals }(P<0.0001)\end{array}$ \\
\hline $\begin{array}{l}\text { Graves et al. } \\
(1999)^{39}\end{array}$ & Normally ageing control individuals $(1,836)$ & $\begin{array}{l}\text { Cross-Cultural Smell } \\
\text { Identification Test }\end{array}$ & $\begin{array}{l}\text { At } 2 \text { year follow-up, patients with anosmia at baseline } \\
\text { had twice the risk of cognitive decline compared to } \\
\text { normosmic individuals }(P<0.0007)\end{array}$ \\
\hline $\begin{array}{l}\text { Growdon et al. } \\
(2015)^{7}\end{array}$ & Cognitively normal (215) & UPSIT & $\begin{array}{l}\text { Thinner entorhinal cortex associated with poorer odour } \\
\text { identification in cognitively normal individuals }(P=.003)\end{array}$ \\
\hline $\begin{array}{l}\text { Hagemeier et al. } \\
(2016)^{79}\end{array}$ & $\begin{array}{l}\text { Normally ageing control individuals (19), } \\
\text { aMCl (19), AD (42) }\end{array}$ & UPSIT & $\begin{array}{l}\text { In participants with aMCl, odour identification correlated } \\
\text { with hippocampal volume }(P<0.038) \text { and amygdala } \\
\text { volume }(P<0.047)\end{array}$ \\
\hline $\begin{array}{l}\text { Lafaille-Magnen } \\
\text { et al. }(2017)^{5}\end{array}$ & $\begin{array}{l}\text { Cognitively normal individuals }(100) \text { with } \\
\text { parent or multiple siblings with AD-like } \\
\text { dementia }\end{array}$ & UPSIT & $\begin{array}{l}\text { CSF biomarkers t-tau: } A \beta_{1-42}(P<0.02) \text { and } P_{181} \text {-tau: } A \beta_{1-42} \\
(P<0.02) \text { associated with poorer odour identification } \\
\text { scores }\end{array}$ \\
\hline $\begin{array}{l}\text { Lehrner et al. } \\
(2009)^{49}\end{array}$ & $\begin{array}{l}\text { aMCI (single domain) (11), aMCl (multiple } \\
\text { domain) (19), and non-amnestic } \mathrm{MCl}(34) \text {, } \\
\text { normally ageing control (40) }\end{array}$ & UPSIT & $\begin{array}{l}\text { Poorer odour identification in amnestic } \mathrm{MCI} \text { multiple } \\
\text { domain than in normal control individuals }(P<0.05)\end{array}$ \\
\hline $\begin{array}{l}\text { Murphy et al. } \\
(1998)^{38}\end{array}$ & $\begin{array}{l}\text { Normally ageing control individuals (27), } \varepsilon 4 \\
\text { carriers (7) and non-carriers (20) }\end{array}$ & $\begin{array}{l}\text { San Diego Odor } \\
\text { Identification Test }\end{array}$ & $\begin{array}{l}\text { Odour identification was significantly poorer in cognitively } \\
\text { normal } \varepsilon 4 \text { carriers than in non-carriers }(P<0.006)\end{array}$ \\
\hline $\begin{array}{l}\text { Murphy et al. } \\
(2003)^{6}\end{array}$ & $\begin{array}{l}\mathrm{AD}(13) \text {, normally ageing control } \\
\text { individuals (22) }\end{array}$ & $\begin{array}{l}\text { San Diego Odor } \\
\text { Identification Test }\end{array}$ & $\begin{array}{l}\text { Odour identification ability predicted left hippocampal } \\
\text { volume loss in } A D(P<0.006)\end{array}$ \\
\hline $\begin{array}{l}\text { Olofsson et al. } \\
(2010)^{40}\end{array}$ & $\begin{array}{l}\text { Normally ageing control individuals, } \varepsilon 4 \\
\text { carriers (372), and non-carriers (864) }\end{array}$ & $\begin{array}{l}\text { Scandinavian Odor } \\
\text { Identification Test }\end{array}$ & $\begin{array}{l}\text { Odour identification poorer in elderly } \varepsilon 4 \text { carriers than } \\
\text { non-carriers }(P=0.033)\end{array}$ \\
\hline $\begin{array}{l}\text { Oleson \& } \\
\text { Murphy }(2015)^{33}\end{array}$ & AD with two $\varepsilon 4$ alleles (51) & $\begin{array}{l}\text { San Diego Odor } \\
\text { Identification Test }\end{array}$ & $\begin{array}{l}\text { Carriers of } \varepsilon 4 / \varepsilon 4 \text { showed poorer odour identification } \\
\text { relative to } \varepsilon 3 / \varepsilon 4 \text { carriers and } \varepsilon 3 / \varepsilon 3 \text { carriers }(P<0.05)\end{array}$ \\
\hline $\begin{array}{l}\text { Quarmley et al. } \\
(2017)^{50}\end{array}$ & $\begin{array}{l}\mathrm{AD}(262) \text {, aMCI (single domain) ( } 80), \text { aMCI } \\
\text { (multiple domain) (70), normally ageing } \\
\text { control individuals (292) }\end{array}$ & $\begin{array}{l}\text { Sniffin' Sticks Odor } \\
\text { Identification Test }\end{array}$ & $\begin{array}{l}\text { Odour identification is poorer in patients with } \mathrm{MCl} \text { than } \\
\text { cognitively normal individuals }(P<0.0001) \text { and poorer } \\
\text { in multiple domain aMCI than single domain }(P<0.023) \text {. } \\
\text { Use of odour identification with Montreal Cognitive } \\
\text { Assessment scores increased diagnostic accuracy }\end{array}$ \\
\hline $\begin{array}{l}\text { Roberts et al. } \\
(2016)^{14}\end{array}$ & $\mathrm{MCl}(1,430)$ & $\begin{array}{l}\text { Brief Smell } \\
\text { Identification Test }\end{array}$ & $\begin{array}{l}\text { Poorer odour identification associated with aMCl and } \\
\text { higher rate of conversion from aMCI to } A D(P<0001)\end{array}$ \\
\hline $\begin{array}{l}\text { Schofield et al. } \\
(2012)^{85}\end{array}$ & $\begin{array}{l}\text { Normally ageing control individuals (29), } \\
\mathrm{MCl}(13), A D(14)\end{array}$ & UPSIT & $\begin{array}{l}\text { Atropine effect on odour identification greater in } \mathrm{MCI} \\
\text { and AD than in normally ageing control individuals } \\
(P<0.001)\end{array}$ \\
\hline $\begin{array}{l}\text { Schubert et al. } \\
(2008)^{51}\end{array}$ & Cognitively normal $(1,920)$ & $\begin{array}{l}\text { San Diego Odor } \\
\text { Identification Test }\end{array}$ & $\begin{array}{l}\text { Greater olfactory impairment predicted higher risk of } \\
\mathrm{MCI}(P<0.001)\end{array}$ \\
\hline $\begin{array}{l}\text { Tabert et al. } \\
(2005)^{47}\end{array}$ & $\begin{array}{l}\mathrm{AD}(100), \mathrm{MCl}(147), \text { normally ageing } \\
\text { control individuals( } 63)\end{array}$ & $\begin{array}{l}\text { UPSIT, Brief Smell } \\
\text { Identification Test, } \\
\text { 10-item odour scale }\end{array}$ & $\begin{array}{l}\text { Score on ten item odour scale predicted conversion to } \\
\mathrm{AD}(P<0.001)\end{array}$ \\
\hline $\begin{array}{l}\text { Vassilaki et al. } \\
(2017)^{75}\end{array}$ & Cognitively normal (829) & $\begin{array}{l}\text { Brief Smell } \\
\text { Identification Test }\end{array}$ & $\begin{array}{l}\text { Lower Brief Smell Identification Test score associated } \\
\text { with amyloid burden, hippocampal volume and } \\
\text { entorhinal cortex thinning in cognitively normal } \\
\text { individuals }(P<0.01)\end{array}$ \\
\hline $\begin{array}{l}\text { Velayudhan } \\
\text { G Loveston } \\
(2009)^{87}\end{array}$ & $\mathrm{AD}(25)$ & UPSIT & $\begin{array}{l}\text { Change in UPSIT score predicted donepezil treatment } \\
\text { outcome }(P<0.001)\end{array}$ \\
\hline
\end{tabular}


Table 1 (cont.) | Odour identification in populations at risk of Alzheimer disease

\begin{tabular}{|c|c|c|c|}
\hline Reference & Population (number of participants) & $\begin{array}{l}\text { Odour identification } \\
\text { test }\end{array}$ & Results \\
\hline $\begin{array}{l}\text { Westervelt et al. } \\
(2008)^{130}\end{array}$ & $\begin{array}{l}\mathrm{AD}(44), \mathrm{MCl}(88) \text {, normally ageing control } \\
\text { individuals (21) }\end{array}$ & $\begin{array}{l}\text { Brief Smell } \\
\text { Identification Test }\end{array}$ & $\begin{array}{l}\text { Odour identification poorer in patients with } \mathrm{MCl} \text { than } \\
\text { control individuals }(P=0.01) \text { and poorer in } \mathrm{AD} \text { than } \mathrm{MCl} \\
(P<0.001) \text {. Subtypes of } \mathrm{MCl} \text { did not differ on Brief Smell } \\
\text { Identification Test }\end{array}$ \\
\hline $\begin{array}{l}\text { Wilson et al. } \\
(2007)^{46}\end{array}$ & Normally ageing control individuals (471) & $\begin{array}{l}\text { Brief Smell } \\
\text { Identification Test }\end{array}$ & $\begin{array}{l}\text { Poor odour identification predicted development of } \mathrm{MCl} \\
\text { in cognitively normal controls }(P<0.001)\end{array}$ \\
\hline $\begin{array}{l}\text { Yaffe et al. } \\
(2017)^{48}\end{array}$ & Cognitively normal $(2,428)$ & $\begin{array}{l}\text { Cross-Cultural Smell } \\
\text { Identification Test }\end{array}$ & $\begin{array}{l}\text { Greater risk of dementia was associated with poor or } \\
\text { moderate odour identification scores in a biracial sample } \\
(P<0.07-0.0001)\end{array}$ \\
\hline
\end{tabular}

$\mathrm{AD}$, Alzheimer Disease; CSF, cerebrospinal fluid; aMCI, amnestic MCI, $\varepsilon 4$, apolipoprotein $\varepsilon 4$; $\mathrm{MCl}$, mild cognitive impairment; UPSIT, University of Pennsylvania Smell Identification Test.

\section{Brain response to olfactory stimuli}

Brain activity can be measured from the surface of the scalp via EEG and, specifically, via detection of the event-related potential (ERP), a measure that is exquisitely sensitive to the timing of the brain's response to a stimulus. Olfactometers that deliver stimuli of short, controlled duration without somatosensory artefacts are required for accurate stimulus delivery ${ }^{65}$. Olfactory ERPs (OERPs) recorded in relation to olfactory stimulation have demonstrated sensitivity to subtle changes in olfactory functioning associated with ageing, disease and APOE status ${ }^{66,67}$. The latency of brain response, quantified by OERPs, is substantially delayed in patients with $\mathrm{AD}^{66}$. The markedly increased difference in latency in the OERPs compared with auditory ERPs reflects the vulnerability of the olfactory system to AD. Furthermore, $A P O E^{\star} \varepsilon 4$ allele carriers show increased latencies and differential topographical distribution of OERP response compared with non-carriers ${ }^{68}$.

Few functional MRI studies of olfactory function have been conducted in patients with $\mathrm{AD}$ or in those at risk of $\mathrm{AD}$; however, studies are beginning to indicate brain areas that are affected during key olfactory tasks. The primary olfactory cortex, amygdala and insula show decreased activation in patients with $\mathrm{AD}$ compared with healthy individuals in a passive odour task ${ }^{69,70}$ and a detection task ${ }^{71}$, and the piriform cortex and entorhinal cortex showed altered activity in patients with $\mathrm{AD}$ compared with healthy individuals when participants judged the quality of an olfactory stimulus ${ }^{72}$. Decreased activation in the primary olfactory cortex has also been reported in $\mathrm{MCI}^{71}$, and functional connectivity between mesial temporal areas and frontal areas is substantially altered in $A P O E^{\star} \varepsilon 4$ allele carriers compared with noncarriers in a recognition memory task $\mathrm{k}^{62}$. Thus, functional MRI demonstrates neural correlates of altered performance in a number of olfactory tasks. Further research investigating brain response during tasks that engage memory areas will be of particular interest.

\section{Underlying mechanisms}

The necessity for involvement of the olfactory cortex, orbital frontal cortex and mesial temporal structures for good performance on an odour identification task probably makes such tasks particularly sensitive to the neuropathology of AD. Processing of tasks that combine odour naming with odour memory has been reported to be lateralized in the left hemisphere. Left hippocampal volume is associated with both verbal memory tasks and odour identification ${ }^{6}$.

Very early neuropathological changes in MTL structures, particularly the entorhinal cortex, might disrupt connections between the hippocampus and the isocortex that are necessary for memory formation ${ }^{16,18}$. Degeneration of the entorhinal cortex affects activity in the hippocampus that is required for odour-related tasks dependent on memory processes. Left hippocampal volume is highly correlated with performance on odour identification in patients with $\mathrm{AD}^{6}$. Indeed, low hippocampal volume and entorhinal cortex thickness are associated with poor odour identification in cognitively normal elderly adults ${ }^{7}$. Thus, structural measures of MTL volume and thickness are reflected in performance on odour identification. Research is needed to determine the sensitivity and specificity of these measures for predicting cognitive decline and AD. Additional functional neuroimaging studies that specifically engage networks involved in odour identification and odour memory are also needed to better understand the mechanisms underlying impairment of odour identification and odour memory in prodromal AD.

Accumulating research suggests that increased brain activation (hyperactivation) during effortful cognitive tasks is associated with $\mathrm{A} \beta$ deposition in individuals at risk of $\mathrm{AD}^{73}$. Greater activation on functional MRI during memory tasks is observed in patients with MCI and in individuals at risk of $\mathrm{AD}$ than in cognitively normal individuals, demonstrating functional compensation in brain areas important for memory, such as the MTL, temporoparietal junction, and posterior cingulate and precuneus. FIGURE 4 illustrates activation in the precuneus in individuals at risk of $\mathrm{AD}$ owing to the $A P O E^{\star} \varepsilon 4$ allele who were performing an odour recognition memory task ${ }^{74}$. FICURE 5 presents a potential model for the central mechanisms underlying olfactory impairment in AD: individuals at risk of $\mathrm{AD}$ who have olfactory dysfunction would be expected to require greater effort to perform well in olfactory tasks, resulting in hyperactivation in olfactory 

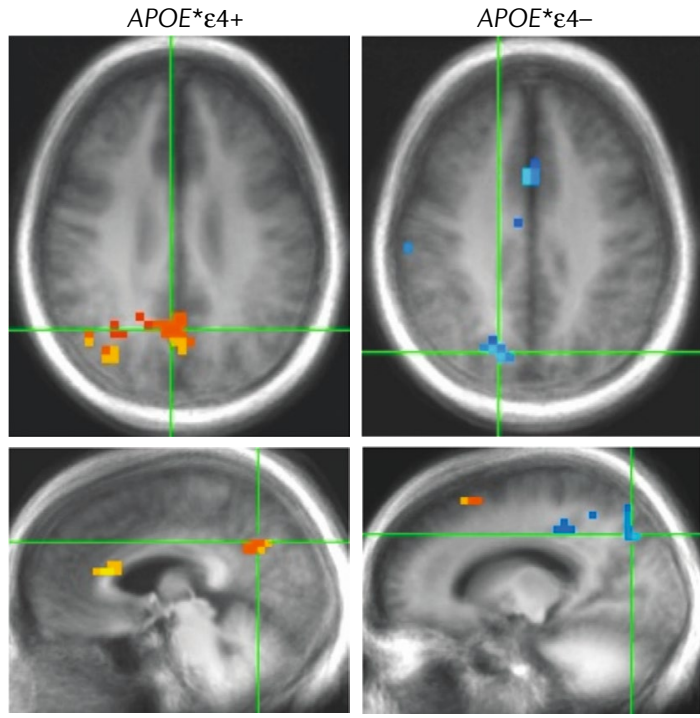

Fig. 4 | Effect of APOE status on brain activation during odour recognition. Functional MRI shows activation in the precuneus in individuals carrying the apolipoprotein $(A P O E)^{\star} \varepsilon 4$ allele during an odour recognition memory task. Increased activation in $A P O E^{\star} \varepsilon 4$ carriers (APOE* $\varepsilon 4+$ ) versus non-carriers (APOE* $\left.\varepsilon^{*} 4\right)$ suggests that increased effortful processing is required to perform the task. Changes in activation in the precuneus occur early in mild cognitive impairment. Warm colours indicate increased activation; cool colours indicate reduced activation.

sensory and cognitive processing areas. Hyperactivation causes degenerative changes that, over the lifespan, will result in decreased entorhinal thickness and hippocampal volume. Over time, performance on odour identification and odour memory tasks will decline further as a result of compromised brain integrity, reflecting the disease process.

\section{Olfactory function and CSF biomarkers}

CSF biomarkers of AD include $A \beta_{1-40}, A \beta_{1-42}$, the ratio of $A \beta_{1-40}: A \beta_{1-42}$, t-tau, $P_{181}$-tau and the ratio of $A \beta: t^{3}$. Over the course of $A D$ progression, levels of $A \beta$ decrease peripherally as the peptide is deposited in the brain. If olfactory function (for example, as assessed by odour identification) is to function as a useful biomarker that can substitute for markers obtained with invasive measures, an understanding of the relationship between olfactory function and CSF biomarkers in prodromal $\mathrm{AD}$ is crucial. One study has reported meaningful relationships between CSF biomarkers and a capacity for odour identification in individuals with heightened risk of $\mathrm{AD}$. In first degree relatives of patients with $\mathrm{AD}$, odour identification ability was reported to be related to the ratio of $t$-tau: $A \beta_{1-42}\left(R_{E F} F^{5}\right)$. CSF t-tau: $A \beta_{1-42}, P_{181}$ tau: $A \beta_{1-42}$, and $t$-tau levels correlated with capacity for odour identification in the overall sample, whereas a relationship with $\mathrm{A} \beta$ alone was present only in the lowest quartile in which almost half of patients were $A P O E^{\star} \varepsilon 4$ carriers. These data suggest that the emergence of tau pathology, whose interaction with amyloid is crucial to disease symptomatology, is related to emerging olfactory dysfunction (FIG. 6). The robust relationship between odour identification and tau parallels the Braak staging of the disease, in which tangles appear in the entorhinal and transentorhinal areas early in the disease process, whereas amyloid appears first in frontal areas ${ }^{18}$. As with CSF measures of amyloid, the relationship between odour identification and positive results on amyloid PET scans is not remarkable. One study found a statistically significant association between increased odds of anosmia and increased amyloid accumulation in cognitively normal participants ${ }^{75}$. In another study, amyloid positive and amyloid negative participants with amnestic MCI did not differ on odour identification ${ }^{76}$ and, in another report, amyloid burden was marginally associated with impaired odour identification in univariate analyses?

\section{Structural measures of brain integrity}

Hippocampal volume and MTL thickness. Reduced hippocampal volume, as assessed by structural MRI, has been proposed as a marker of early pathology and of disease progression in $\mathrm{AD}^{77,78}$. Hippocampal volume is highly correlated with odour identification performance in patients with $\mathrm{AD}^{6}$. By contrast, the Boston Naming Test showed an appreciably lower correlation with hippocampal volume than odour identification, suggesting that odour identification is a better indicator of hippocampal atrophy in patients with $\mathrm{AD}$. A subsequent study reported that lower right hippocampal and left amygdala volume correlated with odour identification performance in amnestic MCI, and bilateral hippocampal and left amygdala volumes correlated with odour identification performance in $\mathrm{AD}$, but no statistically significant correlations were found between MTL structures and University of Pennsylvania Smell Identification Test (UPSIT) scores in healthy control individuals ${ }^{79}$. In addition, reduced hippocampal volume and thinning of entorhinal cortex or a composite MTL signature has been associated with poor odour identification in cognitively normal individuals ${ }^{6,75}$. In one report ${ }^{75}$, abnormal hippocampal volume was significantly associated with odour identification score only in those individuals with abnormal amyloid PET scans, which suggests that amyloid accumulation might be required for odour identification performance to signal preclinical disease. In clinically normal individuals at risk of $\mathrm{AD}$ because of metabolic syndrome, odour identification is correlated with entorhinal thickness ${ }^{80}$. Longitudinal studies are needed to determine the predictive power of olfactory testing for hippocampal atrophy and other structural measures of MTL integrity; however, the current evidence suggests that olfactory tests might be a useful indicator of reduced hippocampal volume and thinning of the entorhinal cortex in preclinical $\mathrm{AD}$, supporting the potential usefulness of this test in identifying individuals at risk of increasing cognitive impairment who might benefit from and enrich clinical trials of disease-modifying therapies.

Olfactory bulb. Olfactory receptor neurons from the olfactory epithelium project to the mitral cells in the glomeruli of the olfactory bulb. Early processing of olfactory information takes place in the bulb. Post-mortem studies 


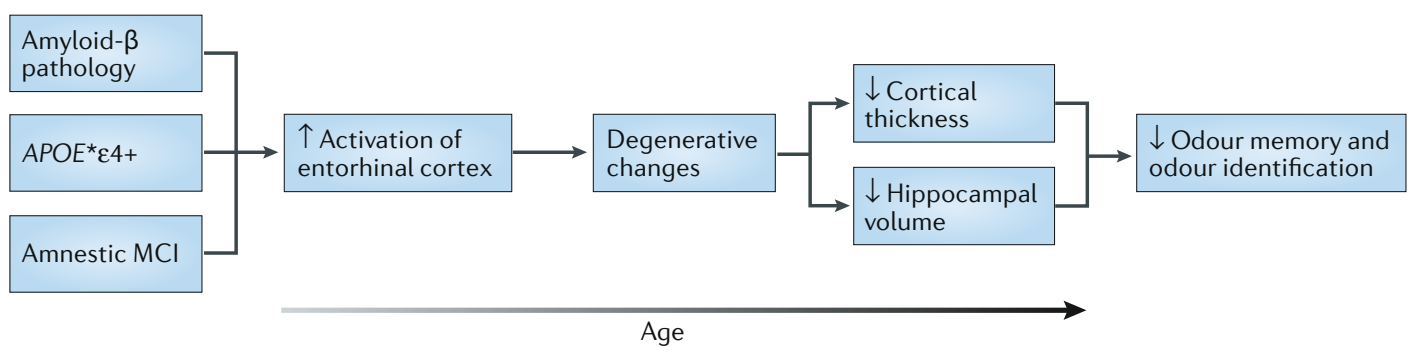

Fig. 5 | Potential mechanism of olfactory impairment in Alzheimer disease. When an individual with olfactory impairment who is at risk of Alzheimer disease (owing to amyloid burden, apolipoprotein (APOE) ${ }^{\star} \varepsilon 4$ or amnestic mild cognitive impairment $(\mathrm{MCl})$ ) attempts to detect, identify or remember an odour, hyperactivation in olfactory sensory and cognitive processing areas - such as the piriform cortex, entorhinal cortex and hippocampus - occurs. Over the lifespan, degenerative changes occur as a result and these changes are associated with thinning in the entorhinal cortex and decreased hippocampal volume.

indicate that the frequency and density of neurofibrillary tangles in the bulb is highly correlated with the frequency and density of tangles in the entorhinal cortex ${ }^{27,81}$. Whether changes in the bulb can be detected in vivo using structural MRI in preclinical and clinical stages of $\mathrm{AD}$ has been investigated, but findings have been inconsistent. One study that reported decreased olfactory bulb volume in $\mathrm{AD}^{82}$ and in $\mathrm{MCI}^{83}$ did not assess olfactory function. Another study reported no decrease in bulb volume in MCI or AD, and no correlation between bulb volume and olfactory function assessed by Sniffin' Sticks (a commercially available odour identification test $)^{84}$. This discrepancy might partially be attributable to the difficulty of measuring olfactory bulb volume. Studies on other patient groups with olfactory loss (for example after an upper respiratory infection, after head trauma or in patients with Parkinson disease) also show inconsistent results. Differences in scan type and disease severity might partially be responsible for the discrepancies; however, further research is warranted to clearly understand the potential for bulb volume to reflect early pathology and its relationship to olfactory performance.

\section{Interventions}

Cholinergic deficits underlying $A D$. Donepezil, a cholinesterase inhibitor, is effective in halting the progression of AD symptoms for $\sim 6$ months to 1 year and is the primary drug prescribed for $\mathrm{AD}$ in clinical practice. Improved odour identification has been suggested as a clinically useful measure to predict response to cholinesterase inhibitor treatment ${ }^{85}$. Two studies have shown improved odour identification with donepezil: a small sample study in patients with cognitive impairment ${ }^{86}$ and another in patients with mild to moderate $\mathrm{AD}^{87}$. In addition to detection of functional decline, the ability to reflect improvement is crucial in therapeutic trials, thus the positive effect of donepezil on olfactory function is of interest.

Hormonal replacement therapy. Hormonal replacement therapy (HRT) administered after AD diagnosis does not reverse the pathology of AD; however, several studies suggest that HRT might be effective in preventing, delaying or minimizing symptoms of $\mathrm{AD}$ if administered during the right window of opportunity ${ }^{88}$. Interestingly, olfactory function is impaired to a lesser degree in elderly women who have had HRT compared with other individuals. Patients with AD who received HRT outperformed those who did not receive HRT on odour memory, yet showed no advantage on visual memory ${ }^{89}$. Further study demonstrated a better odour threshold in $A P O E^{\star} \varepsilon 4$ carriers who did not have dementia and who had received HRT than in those without HRT ${ }^{90}$. Odour thresholds in HRT users with the $A P O E^{\star} \varepsilon 4$ allele were comparable to non-carriers, suggesting that HRT exerted a protective effect in $A P O E^{*} \varepsilon 4$ carriers. No statistically significant differences in thresholds were found as a function of HRT use in non-carriers. A subsequent study also reported better odour memory scores in postmenopausal women on HRT than those with past HRT or no therapy, although sample sizes prevented investigation of an interaction between HRT and $A P O E^{\star} \varepsilon 4$ carrier status ${ }^{91}$.

\section{Clinical application}

Unawareness of olfactory impairment. Patients with $\mathrm{AD}$ are likely to be unaware of olfactory impairment. Unawareness of olfactory dysfunction is associated with cognitive decline in elderly adults without dementia ${ }^{92,93}$ and is associated with cognitive deficits in a number of domains, including verbal learning and memory, and attention and processing speed, as early as middle age $^{94}$. This finding is important for neurologists who will use olfaction as an aid to diagnosis: asking a patient whether they can smell cannot be expected to produce valid and reliable information about whether they have olfactory impairment. To avoid a missed diagnosis, an objective assessment of olfactory function is necessary. Screening with a rapidly-administered test of odour identification is a first step that can reveal the need for more comprehensive testing of olfactory or cognitive function.

Instruments for odour identification screening. Several rapidly administered odour identification tests are available that can serve as screening instruments in a clinic setting (BOX 1). In the USA, the NIH has developed an olfaction test within the NIH Toolbox that is rapidly and inexpensively administered ${ }^{95}$. The Odor Stick Identification Test for Japanese ${ }^{96}$, the San Diego Odor Identification Test ${ }^{97}$ and the Scandinavian Odor Identification Test developed in Sweden ${ }^{98}$ can be rapidly 


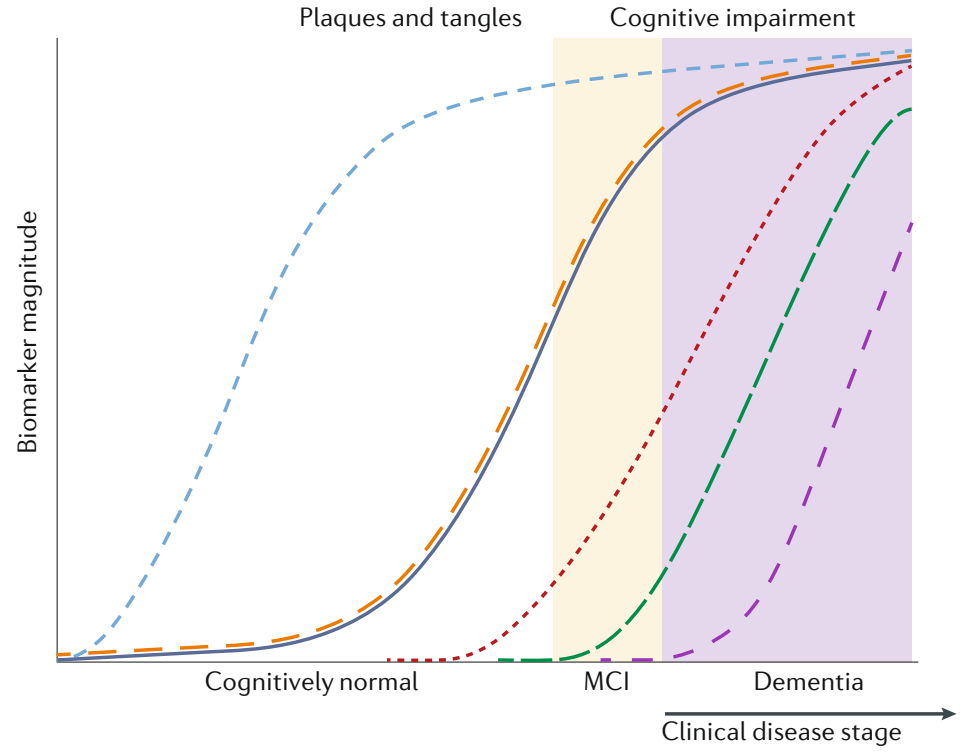

\begin{tabular}{|lrl}
\hline-- - Amyloid $\beta$ & Tau-mediated neuronal & Themory dysfunction \\
& injury and dysfunction
\end{tabular}

Fig. 6 | Proposed emergence of olfactory functional impairment in Alzheimer disease pathological progression. This figure illustrates the emergence of olfactory impairment within the context of the emergence of other indicators of the pathological cascade described by Jack et al. $(2010)^{127} . \mathrm{MCl}$, mild cognitive impairment. Adapted from REF. ${ }^{127}$, Elsevier. olfactory dysfunction, such as in Parkinson disease and Lewy body dementia. Accordingly, the sensitivity and specificity of odour identification tests currently used has negatively influenced their inclusion in clinical assessment and in clinical trials of disease-modifying therapy to date. Thus far, most olfactory testing in these instances has utilized odour identification tests, probably because they are inexpensive and rapidly administered by non-experts. Novel olfactory tests that target the specific brain areas and processes affected earliest in preclinical AD could hold additional promise for early disease detection.

\section{Hearing}

The first reports that hearing is impaired in $\mathrm{AD}$ were published in the $1970 \mathrm{~s}^{28}$. Evidence from a number of epidemiological and population-based studies indicates an association between hearing impairment and dementia or $\mathrm{AD}$, independent of age ${ }^{8-10}$. Hearing loss is highly prevalent in the elderly population, with implications for the sensitivity and specificity of hearing impairment as a potential biomarker.

A number of large cohort studies have now demonstrated an association between self-reported or measured hearing loss and cognitive impairment or dementia ${ }^{8-10,102}$. Cross-sectional assessment revealed a statistically significant association between hearing loss and scores on the Mini-Mental State Examination (MMSE), free recall and executive function in the Baltimore Longitudinal Study of Ageing ${ }^{102}$. The results suggested that the reduction in cognitive function associated with a $25 \mathrm{~dB}$ hearing loss was equivalent to an age-associated loss of 6.8 years of cognitive function. Self-reported hearing aid use was not associated with cognitive scores.

In a prospective study of the Baltimore participants, peripheral hearing loss at baseline was associated with incident dementia followed over time ${ }^{8}$. Greater hearing loss was associated with greater risk of dementia development. The authors raised the important question of whether hearing loss is a marker for early stage dementia or is a modifiable risk factor. The English Longitudinal Study of Ageing (ELSA), a large population study, assessed individuals $\geq 50$ years of age and found that both self-reported hearing difficulty and objective hearing loss were associated with cumulative diagnosed dementia over a 10 -year period. In this study, hearing aid use seemed to have a protective effect ${ }^{9}$. Another study analysed pure-tone air conduction thresholds in well-functioning, communitydwelling adults aged 70-79 years in the Health $A B C$ Study, who were dementia-free at baseline and who self-reported no difficulty with mobility or activities of daily living. Results demonstrated that moderate to severe peripheral hearing loss was associated with a 55\% increase in the risk of dementia after 9 years ${ }^{10}$. The rate of cognitive decline was unrelated to hearing impairment and no statistically significant effect was detected with regards to hearing aid use, although the authors note that in both instances the study might have been underpowered to detect these effects. Impaired hearing at baseline predicted cognitive impairment after 5 years in the Beaver Dam study, although impaired odour 
identification at baseline predicted cognitive impairment after 5 years more accurately than either impaired hearing or impaired vision ${ }^{52}$. A systematic review and meta-analysis of 40 studies that examined associations between hearing loss and cognitive function, cognitive impairment, dementia, vascular dementia or $\mathrm{AD}$ found statistically significant associations in cross-sectional studies examining the relationships between hearing loss and cognitive function, cognitive impairment and dementia; however, the associations between hearing loss and $\mathrm{AD}$ were not significant in either cross-sectional or cohort studies ${ }^{103}$.

\section{Interventions}

Given the association of hearing loss with cognitive impairment, two studies directly addressed the hypothesis that hearing aid use has the potential to reverse cognitive impairment ${ }^{104,105}$. Unfortunately, a 6-month randomized trial of hearing aid use did not produce an improvement in cognitive function in either study; however, further research investigating the parameters of treatment intervention is warranted.

\section{Underlying mechanisms}

A number of potential mechanisms have been proposed for the association between hearing loss and dementia. Evidence from the Baltimore Longitudinal Study of Ageing suggests an association between hearing impairment and the rate of decline in whole brain volume $^{106}$. Regional loss of right temporal lobe volume in patients with dementia suggests a specific loss in areas important for speech processing. Other proposed mechanisms include the effects of social isolation ${ }^{102,107,108}$ and increased cognitive effort, secondary to hearing impairment ${ }^{108}$. Further research is warranted to develop an improved understanding of the mechanisms underlying the link between hearing loss and dementia.

\section{Hearing: conclusions and implications}

Evidence of hearing loss as a potential indicator of cognitive impairment and dementia is mounting. However, it is unclear whether hearing loss is associated with $\mathrm{AD}$, is a causal factor in dementia or is associated with temporal lobe abnormalities or other factors. Whether hearing loss is a modifiable risk factor for $\mathrm{AD}$ is an important question. Additional information on potential mechanisms and interventions targeting hearing loss will be essential to a greater understanding of auditory impairment in dementia and $\mathrm{AD}$.

\section{Vision}

The occurrence of $\mathrm{AD}$ pathology in the visual pathway is well established. $A \beta$ plaques and oligomers have been identified both in post-mortem tissue from patients who had $\mathrm{AD}$ and in primary aqueous humour from individuals without $\mathrm{AD}$ undergoing cataract extraction $^{109}$. The implications of this pathology require further investigation.

\section{Retinal thinning}

Multiple studies have reported retinal thinning in AD. Retinal nerve fibre layer thickness, ganglion cell layer thickness and macular volume have been examined with spectral domain optical coherence tomography in a number of studies in patients with $\mathrm{AD}$, but the results for specific quadrants are mixed ${ }^{110,111}$. A 2016 study, powered to differentiate inter-group variances in thickness of $15 \mu \mathrm{m}$ standard deviations from the mean, investigated retinal thinning in $\mathrm{AD}$, non- $\mathrm{AD}$ dementia, amnestic MCI, Parkinson disease and agematched healthy control individuals and found no difference in retinal markers, including retinal nerve fibre layer thickness, ganglion cell layer thickness and macular volume $\mathrm{e}^{112}$. A subsequent study, with a larger sample size than the first, reported significant thinning of global and temporal superior quadrants of the peripapillary retinal nerve fibre layer in $\mathrm{AD}$ compared with controls ${ }^{113}$. Contrast sensitivity vision, which is poorer in patients with $\mathrm{AD}$ than in healthy controls, is significantly correlated with macular vol$u_{m e}{ }^{114}$. Results of studies of retinal thinning in MCI are emerging but a consistent picture is not yet clear. Retinal thinning has been observed in MCI and was found to be related to memory complaints in amnestic MCI $^{115,116}$ However, patients with MCI had a greater macular volume than patients with $\mathrm{AD}$ or healthy control individuals, which was suggested to be due to inflammation and/or gliosis ${ }^{117}$. Another study found no statistically significant differences in thickness of inner retinal layers, or in macular or optic nerve volumes in patients with $\mathrm{MCI}$ or early-moderate $\mathrm{AD}^{118}$. The authors suggest a number of potential factors that might have influenced their findings, including a potentially insufficient sample size. The exclusion of patients with glaucoma from their study might have been of particular importance as the occurrence of glaucoma has been associated with $\mathrm{AD}$. The degree to which retinal thinning distinguishes between healthy individuals, patients with $\mathrm{MCI}$ and patients with $\mathrm{AD}$, and whether this thinning reflects cognitive function and disease severity are important unanswered questions.

\section{Contrast sensitivity}

Contrast sensitivity is impaired in $\mathrm{AD}^{119,120}$, in $\mathrm{MCI}$ and in individuals with cognitive complaints who do not have performance deficits ${ }^{120}$. The degree of impairment in contrast sensitivity is related to standard cognitive measures such as the California Verbal Learning Test (CVLT), CVLT total score and CVLT long delay recall scores, suggesting the potential for this impairment to signal cognitive decline. Increasing the contrast of visual stimuli to compensate for deficits in contrast sensitivity enables performance to be enhanced on tests of visualdependent cognition such as letter identification, word reading and digit cancellation, suggesting that visual impairment is responsible for some of the apparent cognitive information processing difficulties. However, patients with $\mathrm{AD}$ continue to show poor performance regardless of enhanced contrast level, indicating the cognitive nature of their deficits ${ }^{121}$. Contrast sensitivity might also be associated with amyloid and tau deposition at preclinical stages, according to ${ }^{18} \mathrm{~F}$-florbetapir and ${ }^{18} \mathrm{~F}$-flortaucipir PET scans ${ }^{122}$. 


\section{Pupillary response}

Patients with AD demonstrate abnormal pupillary responses. In fact, supersensitivity of the pupil dilation response to ocular administration of topicamide, an acetylcholine-blocker, has been suggested as a potential biomarker of $\mathrm{AD}^{123}$. The difference in the pupillary light reflex in patients with $\mathrm{AD}$ after treatment with tropicamide was reported to be significantly lower $(1.01 \mathrm{~mm})$ than in healthy controls $(1.42 \mathrm{~mm})$, and significantly correlated with DRS scores ${ }^{123}$. Changes in pupillary response might also be a biomarker of $\mathrm{AD}$ because they reflect the integrity of the locus coeruleus, which has been reported as the site of earliest $\mathrm{AD}$ neuropathology ${ }^{124}$.

Within the past few years, studies have focused on the pupillary response as a reflection of the ability to successfully compensate for increased cognitive load. During cognitive tasks the pupillary diameter reflects cognitive effort until the participant's ability is exceeded. Thus, pupillary response measures have been studied in $\mathrm{AD}$ and MCI. Indeed, patients with MCI show changes in pupillary response and pupil size compared with healthy control individuals, with higher scores on the MMSE associated with a lower light reflex latency and greater increase in amplitude of pupil response ${ }^{125}$. In a study of adults aged 56-66 years, those with amnestic MCI had significantly greater alterations in pupil dilation than those with non-amnestic MCI and cognitively normal adults ${ }^{126}$. However, the sensitivity and specificity of pupillary response as a biomarker for $\mathrm{AD}$ is challenged by the fact that pupillary response is compromised in other conditions such as Parkinson disease.

\section{Vision: conclusions and implications}

The emergence of AD pathology in the peripheral and central visual systems is well established in patients with $\mathrm{AD}$; however, the point at which pathology first appears in the visual system is a matter of discussion. Additional research into the sensitivity and specificity of visual dysfunction in longitudinal studies will be important to establish the clinical utility of visual system impairment in AD.

\section{Conclusions}

The evidence to date suggests that olfaction shows the greatest promise among all sensory biomarkers of $\mathrm{AD}$. A substantial body of research indicates that the impairment of a number of measures of olfactory function can signal the development of the early stages of AD (TABLE 1). Odour identification, odour familiarity and odour recognition memory all show a robust ability to discriminate between cognitively normal individuals, patients with $\mathrm{AD}$, patients with $\mathrm{MCI}$ and those at risk of $\mathrm{AD}^{14,35,38-48}$. Odour identification $^{35,37}$ and odour familiarity (P. Wheeler and C.M., unpublished observations) predict transitions from MCI to AD, particularly in those with a genetic risk of $\mathrm{AD}$, which suggests a potential utility for these measures in clinical trials ${ }^{35}$. Olfactory impairment is associated with measures of reductions in hippocampal volume and entorhinal cortex thinning ${ }^{6,75}$, and may be related to the CSF levels of biomarkers of $\mathrm{AD}^{5}$. The emergence of olfactory impairment as tau levels increase is particularly suggestive of its potential as an early marker of disease. In addition to odour identification, the relative sensitivity and specificity of other promising olfactory tasks, particularly episodic odour recognition memory and remote odour memory, warrant further research.

Auditory impairment has also been associated with the development of cognitive impairment and dementia in epidemiological studies ${ }^{8-10}$, although the available evidence suggests that the sensitivity and specificity of auditory impairment as a marker of AD are lower than for olfaction ${ }^{52}$. To date, efforts to treat auditory impairment have not been shown to reverse or retard the development of dementia ${ }^{104,105}$. Visual deficits, specifically retinal thinning ${ }^{110-113}$, contrast sensitivity ${ }^{119-121}$ and pupillary response $\mathrm{e}^{123,125,126}$ have received some attention as potential markers of AD. However, the extent to which these deficits emerge in the prodromal period is unclear. Additional studies of multiple sensory modalities in the same individuals are needed to further address the relative efficacies of measures of sensory impairment in detecting prodromal AD.

Tremendous interest exists in markers that can signal the early development of AD. Impairments in olfaction, hearing and vision have emerged as potential markers of prodromal $\mathrm{AD}$, and these markers hold great promise as potential early indicators of disease. However, future research is necessary to chart the progression of sensory impairments in the prodromal period, to further examine their relationship to CSF biomarkers and emerging measures of structural and functional MRI, to assess their response to disease-modifying agents and to enhance their sensitivity and specificity for $\mathrm{AD}$ prediction.

Published online 10 December 2018
1. Alzheimer's Disease International. Dementia Statistics. $A D I$ https://www.alz.co.uk/research/statistics (2017).

2. Alzheimer's Association. 2015 Alzheimer's disease facts and figures. Alzheimers Dement. 11, 332-384 (2015).

3. Galasko, D. R. \& Shaw, L. M. CSF biomarkers for Alzheimer disease - approaching consensus. Nat. Rev. Neurol. 13, 131-132 (2017).

4. Weiner, M. W. et al. The Alzheimer's Disease Neuroimaging Initiative 3: continued improvement for clinical trial improvement. Alzheimers Dement. 13, 561-571 (2017).

5. Lafaille-Magnen, M.-E. et al. Odor identification as a biomarker of preclinical $A D$ in older adults at risk. Neurology 89, 327-335 (2017).
6. Murphy, C., Jernigan, T. L. \& Fennema-Notestine, C. Left hippocampal volume loss in Alzheimer's disease is reflected in performance on odor identification: a structural MRI study. J. Int. Neuropsychol. Soc. $\mathbf{9}$ 459-471 (2003).

7. Growdon, M. E. et al. Odor identification and Alzheimer disease biomarkers in clinically normal elderly. Neurology 84, 2153-2160 (2015).

8. Lin, F. R. et al. Hearing loss and incident dementia. Arch. Neurol. 68, 214-220 (2011).

9. Davies, H. R., Cadar, D., Herbert, A., Orrell, M. \& Steptoe, A. Hearing impairment and incident dementia: findings from the England Longitudinal Study of Ageing. J. Am. Geriatr. Soc. 65, 2074-2081 (2017).
10. Deal, J. A. et al. Hearing impairment and incident dementia and cognitive decline in older adults: the health ABC study. J. Gerontol. A Biol. Sci. Med. Sci. 72, 703-709 (2017).

11. Corder, E. H. et al. Gene dose of apolipoprotein E type 4 allele and the risk of Alzheimer's disease in late onset families. Science 261, 921-923 (1993).

12. Albert, M. S. et al. The diagnosis of mild cognitive impairment due to Alzheimer's disease: recommendations from the National Institute on Aging-Alzheimer's Association workgroups on diagnostic guidelines for Alzheimer's disease. Alzheimers Dement. 7, 270-279 (2011).

13. Jak, A. J. et al. Contributions of neuropsychology and neuroimaging to understanding clinical subtypes 
of mild cognitive impairment. Neurobiol. Dementia 84, 81-103 (2009).

14. Roberts, R. O. et al. Association between olfactory dysfunction and amnestic mild cognitive impairment and Alzheimer disease dementia. JAMA Neurol. 16 1-9 (2015).

15. Hyman, B. T., Arriagada, P. V. \& Hoesen, G. W. Pathologic changes in the olfactory system in aging and Alzheimer's disease. Ann. NY Acad. Sci. 640, 14-19 (1991)

16. Braak, H. \& Braak, E. The human entorhinal cortex normal morphology and lamina-specific pathology in various diseases. Neurosci. Res. 15, 6-31 (1992).

17. Braak, H. \& Braak, E. Morphological criteria for the recognition of Alzheimer's disease and the distribution pattern of cortical changes related to this disorder. Neurobiol. Aging 15, 355-356 (1994).

18. Braak, H. \& Braak, E. Frequency of stages of Alzheimer-related lesions in different age categories. Neurobiol. Aging 18, 351-357 (1997).

19. Attems, J., Walker, L. \& Jellinger, K. A. Olfactory bulb involvement in neurodegenerative diseases. Acta Neuropathol. 127, 459-475 (2014).

20. Hyman, B. T. \& Tanzi, R. N. Amyloid, dementia and Alzheimer's disease. Curr. Opin. Neurol. Neurosurgery 5. 88-93 (1992)

21. Hyman, B. T. The neuropathological diagnosis of Alzheimer's disease: clinical-pathological studies. Neurobiol. Aging 18, 27-32 (1997).

22. Ohm, T. G. \& Braak, H. Olfactory bulb changes in Alzheimer's disease. Acta Neuropathol. 73, 365-369 (1987).

23. Struble, R. G. \& Clark, H. B. Olfactory bulb lesions in Alzheimer's disease. Neurobiol. Aging 13, 469-473 (1992).

24. Braak, H. \& Braak, E. Neuropathological stageing of Alzheimer-related changes. Acta Neuropathol. 82 237-259 (1991)

25. Braak, H. \& Braak, E. Staging of Alzheimer-related cortical destruction. Int. Psychogeriatr. 9, 269-272 (1997).

26. Braak, H. \& Del Tredici, K. The pathological process underlying Alzheimer's disease in individuals under thirty. Acta Neuropathol. 121, 171-181 (2011).

27. Price, J. L., Davis, P. B., Morris, J. C. \& White, D. L. The distribution of tangles, plaques and related immunohistochemical markers in healthy aging and Alzheimer's disease. Neurobiol. Aging 12, 295-312 (1991).

28. Waldton, S. Clinical observations of impaired cranial nerve function in senile dementia. Acta Psychiat. Scand. 50, 539-547 (1974).

29. Serby, M. Olfaction and Alzheimer's disease. Prog. Neuropsychopharmacol. Biol. Psychiatry 10, 579-586 (1986)

30. Doty, R. L., Reyes, P. F. \& Gregor, T. Presence of both odor identification and detection deficits in Alzheimer's disease. Brain Res. Bull. 18, 597-600 (1987).

31. Chan, A., Tam, J., Murphy, C., Chiu, H. \& Lam, L. Utility of olfactory identification test for diagnosing Chinese patients with Alzheimer's disease. J. Clin. Exp. Neuropsychol. 24, 251-259 (2002).

32. Morgan, C. D., Nordin, S. \& Murphy, C. Odor identification as an early marker for Alzheimer's disease: impact of lexical functioning and detection sensitivity. J. Clin. Exp. Neuropsychol. 17, 793-803 (1995).

33. Oleson, S. \& Murphy, C. Olfactory dysfunction in $A p o E$ $\varepsilon 4 / 4$ homozygotes with Alzheimer's disease. J. Alzheimers Dis. 46, 791-803 (2015)

34. Woodward, M. R. et al. Validation of olfactory deficit as a biomarker of Alzheimer disease. Neurol. Clin. Practice 7, 5-14 (2017)

35. Albers, M. W. et al. At the interface of sensory and motor dysfunctions and Alzheimer's disease. Alzheimers Dement. 11, 70-98 (2015).

36. Rahayel, S., Frasnelli, J. \& Joubert, S. The effect of Alzheimer's disease and Parkinson's disease on olfaction: a meta-analysis. Behav. Brain Res. 231 60-74 (2012).

37. Roalf, D. R. et al. A quantitative meta-analysis of olfactory dysfunction in mild cognitive impairment. J. Neurol. Neurosurg. Psychiatry 88, 226-232 (2017)

38. Murphy, C., Bacon, A. W., Bondi, M. W. \& Salmon, D. P. Apolipoprotein E status is associated with odor identification deficits in nondemented older persons. Ann. NY Acad. Sci. 855, 744-750 (1998).

39. Graves, A. B. et al. Impaired olfaction as a marker for cognitive decline: interaction with apolipoprotein epsilon4 status. Neurology 53, 1480-1487 (1999).
40. Olofsson, J. K. et al. Odor identification impairment in carriers of $A p o E-\varepsilon 4$ is independent of clinical dementia. Neurobiol. Aging 31, 567-577 (2010).

41. Mattis, S. in Geriatric Psychiatry: A Handbook for Psychiatrists and Primary Care Physicians (eds Bellak, L., Karasu, T. B. \& Birenbaum, C.) 77-121 (Grune \& Stratton, NY, 1976).

42. Calhoun-Haney, R. \& Murphy, C. Apolipoprotein e4 is associated with more rapid decline in odor identification than in odor threshold or dementia rating scale scores. Brain Cogn. 58, 178-182 (2005).

43. Josefsson, M., Larsson, M., Nordin, S., Adolfsson, R. \& Olofsson, J. APOE-e4 effects on longitudinal decline in olfactory and non-olfactory cognitive abilities in middle-aged and old adults. Scientif. Rep. 7, 1286 (2017).

44. Devanand, D. P. et al. Olfactory identification deficits and $\mathrm{MCl}$ in a multi-ethnic elderly community sample. Neurobiol. Aging 31, 1593-1600 (2010).

45. Djordjevic, J., Jones-Gotman, M., De Sousa, K. \& Chertkow, $\mathrm{H}$. Olfaction in patients with mild cognitive impairment and Alzheimer's disease. Neurobiol. Aging 29, 693-706 (2008)

46. Wilson, R. S. et al. Olfactory identification and incidence of mild cognitive impairment in older age. Arch. General Psychiatry 64, 802-808 (2007).

47. Tabert, M. H. et al. A 10-item smell identification scale related to risk for Alzheimer's disease. Ann. Neurol. 58, 155-160 (2005)

48. Yaffe, K., Freimer, D. $₫$ Chen, H. Olfaction and risk of dementia in a biracial cohort of older adults. Neurology 88, 456-462 (2017).

49. Lehrner, J., Pusswald, G., Gleiss, A., Auff, E. \& Dal-Bianco, P. Odor identification and self-reported olfactory functioning in patients with subtypes of mild cognitive impairment. Clin. Neuropsychol. 23, 818-830 (2009).

50. Quarmley, M. et al. Odor identification screening improves diagnostic classification in incipient Alzheimer's Disease. J. Alzheimers Dis. 55, 1497-1507 (2017).

51. Schubert, C. R. et al. Olfaction and the 5-year incidence of cognitive impairment in an epidemiological study of older adults. J. Am. Geriatr. Soc. 56, 1517-1521 (2008).

52. Fischer, M. E. et al. Age-related sensory impairments and risk of cognitive impairment. J. Am. Geriatr. Soc. 64, 1981-1987 (2016)

53. Devanand, D. P., Less, S. \& Manly, J. Olfactory deficits predict cognitive decline and Alzheimer dementia in an urban community. Neurology 84, 182-189 (2015).

54. Murphy, C., Nordin, S. \& Acosta, L. Odor learning, recall, and recognition memory in young and elderly adults. Neuropsychology 11, 126-137 (1997)

55. Delis, D. C., Kramer, J. H., Kaplan, E. \& Ober, B. A. The California Verbal Learning Test (Psychological Corporation, 1987).

56. Nordin, S. \& Murphy, C. Impaired sensory and cognitive olfactory function in questionable Alzheimer's disease. Neuropsychology 10, 113-119 (1996).

57. Gilbert, P. E. \& Murphy, C. The effect of the $A p o E \varepsilon 4$ allele on recognition memory for olfactory and visua stimuli in patients with pathologically confirmed Alzheimer's disease, probable Alzheimer's disease and healthy elderly controls. J. Exp. Clin. Neuropsychol. 26, 779-794 (2004)

58. Gilbert, P. E. \& Murphy, C. Differences between recognition memory and remote memory for olfactory and visual stimuli in nondemented elderly individuals genetically at risk for Alzheimer's disease. Exp. Gerontol. 39, 433-441 (2004).

59. Sundermann, E., Gilbert, P. E. \& Murphy, C. Apolipoprotein $\mathrm{E} \varepsilon 4$ genotype and gender: effects on memory. Am. J. Geriatr. Psychiatry 15, 869-878 (2007).

60. Albers, A. D. et al. Episodic memory of odors stratifies Alzheimer biomarkers in normal elderly. Ann. Neurol. 8, 846-857 (2016)

61. Gilbert, P. E., Barr, J. \& Murphy, C. Differences in olfactory and visual memory in patients with pathologically confirmed Alzheimer's disease and the Lewy body variant of Alzheimer's disease. J. Int Neuropsychol. Soc. 10, 835-842 (2004).

62. Haase, L., Wang, M., Green, E. \& Murphy, C. Functional connectivity during recognition memory in individuals genetically at risk for Alzheimer's disease. Hum. Brain Mapp. 34, 530-542 (2013).

63. Murphy, C. et al. Olfactory thresholds are associated with degree of dementia in Alzheimer's disease. Neurobiol. Aging 11, 465-469 (1990).
64. Bacon, A. W., Bondi, M. W., Salmon, D. P. \& Murphy, $C$. Very early changes in olfactory functioning due to Alzheimer's disease and the role of apolipoprotein E in olfaction. Ann. NY Acad. Sci. 30, 723-731 (1998).

65. Lorig, T. S., Elmes, D. G., Zald, D. H. \& Pardo, J. V. A computer-controlled olfactometer for fMRI and electrophysiological studies of olfaction. Behav. Res. Methods, Instruments, Computers 31, 370-375 (1999)

66. Morgan, C. D. \& Murphy, C. Olfactory event-related potentials in Alzheimer's disease. J. Int Neuropsychol. Soc. 8, 753-763 (2002).

67. Morgan, C. \& Murphy, C. Individuals at risk for Alzheimer's disease show differential patterns of ERP brain activity during odour identification. Behav. Brain Funct. 8, 37 (2012).

68. Murphy, C., Solomon, E. S., Haase, L., Wang, M. \& Morgan, C. D. Olfaction in aging and Alzheimer's disease: event-related potentials to a cross-modal odor recognition memory task discriminate ApoE 4+ and ApoE 4- individuals. Ann. NY Acad. Sci. 1170 647-657 (2009).

69. Kareken, D. A. et al. Olfactory system activation from sniffing: effects in piriform and orbitofrontal cortex. Neurolmage 22, 456-465 (2004).

70. Wang, J. E. et al. Olfactory deficit detected by fMRI in early Alzheimer's disease. Brain Res. 1357, 184-194 (2010).

71. Vasavada, M. M. et al. Central olfactory dysfunction in Alzheimer's disease and mild cognitive impairment: a functional MRI study. J. Alzheimers Dis. 59, 359-368 (2017).

72. Li, W., Howard, J. D. \& Gottfried, J. A. Disruption of odour quality coding in piriform cortex mediates olfactory deficits in Alzheimer's disease. Brain 133 2714-2716 (2010)

73. Mormino, E. C. et al. A $\beta$ deposition in aging is associated with increases in brain activation during successful memory encoding. Cerebral Cortex 22, 1813-1823 (2011).

74. Woodward, J. L. et al. Semantic memory activation in amnestic mild cognitive impairment. Brain 132, 20168-20178 (2009)

75. Vassilaki, M. et al. Neuroimaging biomarkers and impaired olfaction in cognitively normal individuals. Ann. Neurol. 81, 871-882 (2017).

76. Bahar-Fuchs, A. et al. Olfactory deficits and amyloid- $\beta$ burden in Alzheimer's disease, mild cognitive impairment, and healthy aging: a PiB PET study. J. Alzheimers Dis. 22, 1081-1087 (2010).

77. McEvoy, L. K. et al. Mild cognitive impairment: baseline and longitudinal structural MR imaging measures improve predictive prognosis. Radiology 259, 834-843 (2011).

78. McEvoy, L. K. et al. Alzheimer disease: quantitative structural neuroimaging for detection and prediction of clinical and structural changes in mild cognitive impairment. Radiology 251, 195-120 (2009).

79. Hagemeier, J. et al. Odor identification deficit in mild cognitive impairment and Alzheimer's disease is associated with hippocampal and deep gray matter atrophy. Psychiatry Res.Neuroimaging 255, 87-93 (2016).

80. Murphy, C. et al. Olfactory function and structural integrity of entorhinal cortex and hippocampus in non-demented middle-aged and older adults at risk for Alzheimer's disease [abstract 203]. Chem. Senses 41, e1-e110 (2016)

81. Christen-Zaech, S. et al. Early olfactory involvement in Alzheimer's disease. Can. J. Neurol. Sci. 30, 20-25 (2003).

82. Thomann, P. A. et al. Reduced olfactory bulb and tract volume in early Alzheimer's disease-a MRI study. Neurobiol. Aging 30, 838-841 (2009).

83. Thomann, P. A. et al. MRI-derived atrophy of the olfactory bulb and tract in mild cognitive impairment and Alzheimer's disease. J. Alzheimers Dis. 17 213-221 (2009).

84. Servello, A. et al. Olfactory dysfunction, olfactory bulb volume and Alzheimer's disease: is there a correlation? a pilot study 1. J. Alzheimers Dis. 48, 395-402 (2015).

85. Schofield, P. W., Ebrahimi, H., Jones, A. L., Bateman, G. A. \& Murray, S. R. An olfactory 'stress test' may detect preclinical Alzheimer's disease. BMC 12, 24 (2012)

86. Pelton, G. H., Soleimani, L., Roose, S. P., Tabert, M. H. \& Devanand, M. D. Olfactory deficits predict cognitive improvement on donepezil in patients with depression and cognitive impairment: a randomized controlled pilot study. Alzheimer Dis. Assoc. Disord. 30, 67-69 (2016). 
87. Velayudhan, L \& Lovestone, S. Smell identification test as a treatment response marker in patients with Alzhiemer disease receiving donepezil. J. Clin. Psychopharmacol. 29, 387-390 (2009)

88. Brinton, R. D. Estrogen regulation of glucose metabolism and mitochondrial function: therapeutic implications for prevention of Alzheimer's disease. Adv. Drug Deliv. Rev. 60, 1504-1511 (2008)

89. Sundermann, E., Gilbert, P. E. \& Murphy, C. Estrogen and performance in recognition memory for olfactory and visual stimuli in females diagnosed with Alzheimer's disease. J. Int. Neuropsychol. Soc. 12, 400-404 (2006)

90. Sundermann, E. E., Gilbert, P. E. \& Murphy, C. The effect of hormone therapy on olfactory sensitivity is dependent on apolipoprotein E genotype. Horm. Behav. 54, 528-533 (2008).

91. Doty, R. L. et al. Influences of hormone replacement therapy on olfactory and cognitive function in postmenopausal women. Neurobiol. Aging. 36 2053-2059 (2015)

92. Nordin, S., Monsch, A. U. \& Murphy, C. Unawareness of smell loss in normal aging and Alzheimer's disease: discrepancy between self-reported and diagnosed smell sensitivity. J. Gerontol. B Psychol. Sci. Soc. Sci. 50, 187-192 (1995)

93. Devanand, D. P. et al. Olfactory deficits in patients with mild cognitive impairment predict Alzheimer's disease at follow-up. Am. J. Psychiatry 157 1399-1405 (2000).

94. Wehling, E., Nordin, S., Espeseth, T., Reinvang, I. \& Lundervold, A. J. Unawareness of olfactory dysfunction and its association with cognitive functioning in middle aged and old adults. Arch. Clin. Neuropsychol. 26, 260-269 (2011).

95. Dalton, P. et al. Olfactory assessment using the $\mathrm{NIH}$ Toolbox. Neurology 80, 32-36 (2013).

96. Saito, S., Ayabe-Kanamura, S. \& Takashima, Y. Development of a smell identification test using a novel stick-type odour presentation kit. Chem. Senses 31, 379-391 (2006)

97. Murphy, C. et al. Prevalence of olfactory impairment in older adults. JAMA 288, 2307-2312 (2002)

98. Nordin, S., Brämerson, A., Liden, E. \& Bende, M The Scandinavian Odor-Identification Test: development, reliability, validity and normative data. Acta Otolaryngol. 118, 226-234 (1998)

99. Hummel, T., Sekinger, B., Wolf, S. R., Pauli, E. \& Kobal, G. 'Sniffin' sticks': olfactory performance assessed by the combined testing of odor identification, odor discrimination and olfactory threshold. Chem. Senses 22, 39-52 (1997).

100. Doty, R. L., Shaman, P. \& Dann, M. Development of the University of Pennsylvania Smell Identification Test: a standardized microencapsulated test of olfactory function. Physiol. Behav. 32, 489-502 (1984).

101. Christensen, T., Larsson, E.-M., Holm, I. D. Nielsen, O. B. F. \& Andersen, S. Olfactory testing in consecutive patients referred with suspected dementia. BMC Geriatr. 17, 129 (2017).
102. Lin, F. R et al. Hearing loss and cognition in the Baltimore Longitudinal Study of Aging. Neuropsychology 25, 763-770 (2011)

103. Loughrey, D. G., Kelly, M. E., Kelley, G. A., Brennan, S $\&$ Lawlor, B. A. Association of age-related hearing loss with cognitive function, cognitive impairment, and dementia: a systematic review and meta-analysis. JAMA Otolaryngol. Head Neck Surg. 2513, 1-12 (2017).

104. Adrait, A. et al. Do hearing aids influence behavioral and psychological symptoms of dementia and quality of life in hearing impaired Alzheimer's disease patients and their caregivers? J. Alzheimers Dis. 58, 109-121 (2017).

105. Nguyen, M. F. et al. Efficacy of hearing aids on the cognitive status of patients with Alzheimer's disease and hearing loss: a multicenter controlled randomized trial. J. Alzheimers Dis. 58, 123-137 (2017).

106. Lin, F. R. et al. Association of hearing impairment with brain volume changes in older adults. Neuroimage $\mathbf{9 0}$ 84-92 (2014).

107. Weinstein, B. E. \& Ventry, I. M. Hearing impairment and social isolation in the elderly. J. Speech Hear. Res. 25, 593-599 (1982)

108. Lin, F. R. \& Albert, A. Hearing loss and dementia who's listening. Aging Mental Health, 18, 671-673 (2014).

109. Goldstein, L. E. et al. Cytosolic $\beta$-amyloid deposition and supranuclear cataracts in lenses from people with Alzheimer's disease. Lancet 361, 1258-1265 (2003)

110. Iseri, P. K., Altinas, O., Tokay, T. \& Yuksel, N. Relationship between cognitive impairment and retinal morphological and visual functional abnormalities in Alzheimer's disease. J. Neuroophthalmol. 26, 18-24 (2006).

111. Beshira, F., Feke, G. T., Trempe, C. L., McMeel, J. W. $\&$ Schepens, C. L. Retinal abnormalities in early Alzheimer's disease. Invest. Ophthalmol. Vis. Sci. 48, 2285-2289 (2007).

112. Pillai, J. A. et al. Retinal nerve fiber layer thinning in Alzheimer's disease: a case-control study in comparison to normal aging. Parkinson's disease, and non-Alzheimer's dementia. Am. J. Alzheimers Dis. Other Demen. 31, 430-436 (2016)

113. Cunha, J. P. et al. OCT in Alzheimer's disease: thinning of the RNFL and superior hemiretina. Graefes Arch. Clin. Exp. Ophthalmol. 255, 1827-1835 (2017).

114. Polo, V. et al. Visual function and its correlation with retinal changes in patients with Alzheimer's disease. Eye 31, 1034-1041 (2017).

115. Paquet, C. et al. Abnormal retinal thickness in patients with mild cognitive impairment and Alzheimer's disease. Neurosci. Lett. 420, 97-99 (2007).

116. Kesler, A., Vakhapova, V., Korczyn, A. D., Naftaliev, E. $\&$ Neudorfer, M. Retinal thickness in patients with mild cognitive impairment and Alzheimer's disease. Clin. Neurol. Neurosurg. 113, 523-526 (2011).

117. Ascaso, F. J. et al. Reginal alterations in mild cognitive impairment and Alzheimer's disease: an optical coherence tomography study. J. Neurol. 261, 1522-1530 (2014).
118. Lad, E. M. et al. Evaluation of inner retinal layers as biomarkers in mild cognitive impairment to moderate Alzheimer's disease. PLOS ONE 13, e0192646 (2018).

119. Gilmore, G. C., Groth, K. E. \& Thomas, C. W. Stimulus contrast and word reading speed in Alzheimer's disease. Exp. Aging Res. 31, 15-33 (2005).

120. Risacher, S. L. et al. Visual contrast sensitivity in Alzheimer's disease, mild cognitive impairement, and older adults with cognitive complaints. Neurobiol. Aging 34, 1133-1144 (2013).

121. Toner, C. K. et al. Vision-fair neuropsychological assessment in normal aging, Parkinson's disease and Alzheimer's disease. Psychol. Aging 27, 785-790 (2012).

122. Risacher, S. L. et al. Visual contrast sensitivity is associated with amyloid and tau deposition. Alzheimers Dement. 13, 154-155 (2017).

123. Granholm, E. et al. Tropicamide effects on pupil size and pupillary light reflexes in Alzheimer's and Parkinson's disease. Int. J. Psychophysiol. 47, 95-115 (2003).

124. Braak, H. \& Del Tredici, K. Where, when, and in what form does sporadic Alzheimer's disease begin? Curr. Opin. Neurol. 15, 708-714 (2012).

125. Bittner, D. M., Wieseler, I., Wilhelm, H., Riepe, M. W. \& Müller, N. G. Repetitive pupil light reflex: potential marker in Alzheimer's disease? J. Alzheimers Dis. 42 1469-1477 (2014).

126. Granholm, E. L. et al. Pupillary responses as a biomarker of early risk for Alzheimer's disease. J. Alzheimer' Dis. 56, 1419-1428 (2017).

127. Jack, C. R. et al. Hypothetical model of dynamic biomarkers of the Alzheimer's pathological cascade. Lancet Neurol. 9, 119-128 (2010).

128. Conti, M. Z. et al. Odor identification deficit predicts clinical conversion from mild cognitive impairment to dementia due to Alzheimer's disease. Arch. Clin. Neuropsychol. 18, 391-399 (2013).

129. Eibenstein, A. et al. Olfactory screening test in mild cognitive impairment. Neurol. Sci. 26, 156-160 (2005).

130. Westervelt, H. J., Bruce, J. M., Coon, W. G. \& Tremont, C. Odor identification in mild cognitive impairment subtypes. J. Clin. Exp. Neuropsychol. 30, 151-156 (2008)

\section{Acknowledgements}

The author is supported by NIH grant R01 AG004085-26 from the National Institute on Aging. The author gratefully acknowledges C. Frank, A. Jacobson, M. Boquet, E. Farley and J. Liu for research assistance, and the patients and staff of the UCSD ADRC, particularly D. Salmon and D. Galasko and the late $\mathrm{L}$. Thal and R. Katzman.

\section{Competing interests}

The author declares no competing interests.

Publisher's note

Springer Nature remains neutral with regard to jurisdictional claims in published maps and institutional affiliations. 